NBER WORKING PAPER SERIES

\title{
HOW DO COPAYMENT COUPONS AFFECT BRANDED DRUG PRICES AND QUANTITIES PURCHASED?
}

\author{
Leemore Dafny \\ Kate Ho \\ Edward Kong \\ Working Paper 29735 \\ http://www.nber.org/papers/w29735 \\ NATIONAL BUREAU OF ECONOMIC RESEARCH \\ 1050 Massachusetts Avenue \\ Cambridge, MA 02138
}

February 2022, Revised April 2023

We are grateful for comments from Hanming Fang, Craig Garthwaite, Benjamin Handel, Alex Olssen, David Ridley, Amanda Starc, and seminar participants at New York University, Stanford University, University of Pennsylvania (Wharton), Yale University School of Management, the NBER Summer Institute, UCLA (Anderson), Cornell (Brooks), the American Society of Health Economics Annual Meeting, and the American Economics Association Annual Meetings for helpful comments. We thank Amina Abdu, Teresa Rokos, Olivia Zhao, and Ran Zhuo for excellent research assistance. We especially thank Chris Ody for insightful comments and data contributions. Edward Kong received funding from NIA training grant (T32AG51108). The views expressed herein are those of the authors and do not necessarily reflect the views of the National Bureau of Economic Research.

At least one co-author has disclosed additional relationships of potential relevance for this research. Further information is available online at http://www.nber.org/papers/w29735

NBER working papers are circulated for discussion and comment purposes. They have not been peer-reviewed or been subject to the review by the NBER Board of Directors that accompanies official NBER publications.

(C) 2022 by Leemore Dafny, Kate Ho, and Edward Kong. All rights reserved. Short sections of text, not to exceed two paragraphs, may be quoted without explicit permission provided that full credit, including $\odot$ notice, is given to the source. 
How Do Copayment Coupons Affect Branded Drug Prices and Quantities Purchased?

Leemore Dafny, Kate Ho, and Edward Kong

NBER Working Paper No. 29735

February 2022, Revised April 2023

JEL No. I11,I13,L13

\section{$\underline{\text { ABSTRACT }}$}

We estimate the causal effects of drug copayment coupons, which reduce consumer cost-sharing for branded prescription drugs, on net-of-rebate price and quantities sold. Focusing on drugs without generic substitutes, we show that coupon introductions increase quantity sold by $23-25 \%$ for the commercial segment relative to Medicare Advantage, where coupons are banned. To quantify the resulting equilibrium price effects, we estimate a discrete choice model of demand for multiple sclerosis drugs and simulate a model of drug price negotiations. We estimate that net-of-rebate prices are $8 \%$ higher due to the availability of coupons for most of these drugs.

Leemore Dafny

Harvard Business School

Harvard Kennedy School

Morgan Hall 481

Soldiers Field

Boston, MA 02163

and NBER

ldafny@hbs.edu

Kate Ho

Princeton University

Department of Economics

237 Julis Romo Rabinowitz Building

Princeton, NJ 08544

and NBER

kate.ho@princeton.edu
Edward Kong

Harvard University

Department of Economics

1805 Cambridge St

Cambridge, MA 02138

edkong@nber.org

A data appendix is available at http://www.nber.org/data-appendix/w29735 


\section{Introduction}

Public concern over high and rising prescription drug prices in the U.S. has grown increasingly intense over the past decade. There are multiple drivers of this phenomenon, including the rise of high-deductible plans which expose consumers to drug prices, highprofile examples of price hikes for old drugs (e.g., Turing Pharmaceuticals and Daraprim), steady price increases (e.g., Mylan and EpiPen), and higher launch prices for new drugs. In 2021, a RAND study estimated that net prices for branded drugs in the US were nearly twice as high as in 32 other countries (Mulcahy et al., 2021).The 2022 Inflation Reduction Act included provisions to restrain the price growth of drugs after their launch and reduce prices for certain drugs after a period of market exclusivity, although these new provisions only apply to Medicare.

In this study, we consider a rarely mentioned potential driver of high and rising prices in the U.S.: drug copayment coupons. These popular programs (also known as "copay cards") defray consumers' out-of-pocket cost-sharing at the point of purchase. Coupon availability has accelerated rapidly since they first appeared in the early 2000s: Dafny et al. (2017) report that the share of branded drug spending with a coupon increased from 26 percent to 54 percent between June 2007 and December 2010. We extend this time series and find the share increased to 93 percent by 2017. Similarly, the number of drugs with coupons has soared, from about 200 in 2008 to over 800 in 2018 .

While coupons may enable individual consumers to access drugs they couldn't otherwise afford, they may also lead to higher medication prices and insurance premiums. Coupons diminish price competition among drugs and limit insurers' ability to manage drug utilization via tiered formularies. Under tiering, preferred drugs are assigned to lower tiers with lower patient cost-sharing, e.g., $\$ 5$ for generics, $\$ 25$ for preferred brands in Tier 1, and $\$ 50$ for non-preferred brands in Tier 2, etc. In the absence of coupons or other copay-assistance programs, insurers could negotiate lower prices for drugs in exchange for placing them in lower tiers. Tiering also enables insurers to discourage utilization of drugs with cheaper options (e.g., two separate generic medications rather than a single, branded combination of the two).

The rise of coupons has reduced the ability of tiering and cost-sharing to contain spending. By 2014, the Chief Medical Officer of CVS, one of the largest pharmacy benefit managers, wrote that "traditional tiered formularies are becoming less effective in the face of manufacturers' copayment or coupon programs, which continue to pro- 
liferate" (Lotvin et al., 2014). To assess the growth in coupons, we build a database of coupon introductions spanning a decade, using historical snapshots of multiple online databases supplemented by manual searches. We find that the reach of coupons has increased substantially. As tiering has become less effective, insurers have increasingly turned to step-therapy programs, requiring patients to undergo specific regimens or to "fail first" using certain medications or treatments before approving coverage for a drug. Prior authorization requirements and complete exclusion of drugs from formularies are also increasingly common. Indeed, recent research finds that couponed drugs are more likely to be excluded from coverage (Agha et al., 2020).

Although prior researchers have highlighted the mechanisms through which coupons may drive higher prices and spending, we are aware of just three empirical studies of the impact of coupons, and two of these are limited to a special case: coupons for multisource drugs, which are branded drugs with bioequivalent generics (Lee, 2020; Dafny et al., 2017). Lee (2020) simulates the impact of a single (hypothetical) coupon for Zocor, a branded statin with a bioequivalent generic available during the study period. Dafny et al. (2017) examines the effect of copay coupons on the "generic efficiency ratio", the share of prescriptions for a given drug that are dispensed as generic when both brand and generic are available. Using a difference-in-differences strategy that exploits cross-state variation in the legality of coupons for multi-source brands, they find that coupons decrease generic efficiency ratios. Medicare enrollees are prohibited from using branded drug coupons in all states, so they serve as an additional control group for triple difference models. Given the very high rates of generic efficiency in the U.S., however, the aggregate impact of coupons is likely to be greater for drugs without bioequivalent generics (i.e., single-source drugs). No states ban coupons for these medications, necessitating a different identification strategy.

The sole study considering coupons for single-source drugs, (Jordan et al., 2020), finds evidence that coupon users are less likely to abandon prescriptions at retail pharmacies, and this is true even if the coupon doesn't reduce a patient's out-of-pocket cost. Our study builds on Dafny et al. (2017) and Jordan et al. (2020) by identifying the effects of coupon introductions for single-source drugs, estimating a model of drug demand that can account for both price and non-price (henceforth, "advertising") effects of coupons, and simulating the equilibrium price effect of a coupon ban.

We use two complementary approaches to study the impact of copay coupons on prices and quantities of "single-source" branded drugs. First, we estimate a difference- 
in-differences model that quantifies the impact of coupon introductions by comparing pre- vs. post-coupon prices and quantities for the commercially insured vs. the Medicare Advantage population. Medicare Advantage enrollees, who are not permitted to redeem coupons, serve as a natural drug-specific control group. Second, we estimate a demand model for a specific drug segment (medications for multiple sclerosis), and use the estimates as an input to a simulated bargaining model that predicts the equilibrium effect of coupons on prices. The model shows that the effect on price of introducing coupons for drugs without perfect substitutes is theoretically ambiguous.

The difference-in-differences analysis is performed using proprietary data at the drug-month-segment level (where segment is commercial or Medicare Advantage) from one of the largest pharmacy benefit managers, for the period January 2014-June 2017. Pharmacy benefit managers, or PBMs, are firms that manage prescription drug benefits for large employers and for health plans, including commercial as well as Medicare and Medicaid plans. A key role of PBMs is to negotiate discounts (some of which are called "rebates") for drugs purchased by plan enrollees. The price variable we use is net of rebates and discounts, a significant advantage relative to the vast majority of prior studies analyzing drug prices. Because data constraints limit the post-period to 12 months, our analysis only assesses the short-term effect of coupons. Moreover, this effect may be conservative. Branded drugs typically have coupons at launch. Drugs with relatively late coupon introductions may be those for which coupons are expected to have the least impact on manufacturer revenues. Nonetheless, we find substantial quantity effects: coupon introduction is followed by an almost immediate quantity surge of over 20 percent. We do not find changes in relative net-of-rebate prices, which may be due to the short time series used in this analysis. Because list prices are the same for both customer segments, a relative change in net-of-rebate price for the commercial versus the Medicare Advantage segment would require a renegotiation of segment-specific rebates.

Our second analysis is better-suited for examining the equilibrium price effect of coupons. The analysis incorporates rich detail on a specific drug category - diseasemodifying therapies for multiple sclerosis (MS) - and incorporates a fully specified model of demand and insurer-manufacturer negotiations over prices, allowing us to simulate a key policy option: banning coupons. We estimate demand using claims data from 2009 through 2017 from the Health Care Cost Institute, which covers roughly 25\% of commercially insured individuals and 35\% of Medicare Advantage enrollees in the 
U.S. ${ }^{1}$ The simulations indicate that prices of MS drugs are around $8 \%$ higher during the 2015-2017 period due to the availability of coupons, which drive demand through two mechanisms: (1) reducing patients' price elasticity and (2) a non-price effect, which we call an "advertising" effect. We document the distributional impacts of a ban, which lowers out-of-pocket spending for those whose cost-sharing varies with price and lowers premiums for all, but increases out-of-pocket spending for commercially insured individuals who previously used coupons. We predict that total savings (for the MS drug market) would outweigh the increase in out-of-pocket payments by 4 to 1 . We discuss potential mechanisms to address the distributional consequences of a ban.

The paper proceeds as follows. Section 1 provides background information on copay coupons, multiple sclerosis, and related literature. Section 2 presents our differencein-differences analysis of the impact of coupon introductions. In Section 3, we build a model that serves as the foundation for our demand estimation and counterfactual simulations. Section 4 presents our data and demand estimates. Section 5 presents counterfactual simulations for a policy that bans coupons and examines sensitivity of the predictions to different assumptions. We discuss the implications of our findings in Section 6.

\section{Background}

\subsection{Drug Coupons}

A copay coupon is an offer by a manufacturer to pay some or all of a consumer's copay for the manufacturer's drug. By offering a copay coupon, a manufacturer can reduce the out-of-pocket price for its drug, as well as any difference between the out-ofpocket price for its drug and competing drugs, thereby encouraging consumers to buy the manufacturer's drug. Manufacturers' coupons pertain to specific (branded) drugs, and may not be utilized by individuals purchasing drugs with public health insurance such as Medicare. ${ }^{2}$ Manufacturers advertise their coupons on drug-specific websites. Individuals can locate coupons online or in printed media; doctors can also distribute

\footnotetext{
${ }^{1}$ Health Care Cost Institute (2009-2017). "HCCI Commercial Claims Data." Last accessed September $22,2022$.

${ }^{2}$ The federal Anti-Kickback Statute prohibits manufacturers from providing anything of value that may induce a purchase or service financed by a federal health care program. However, manufacturers may donate to independent charitable foundations that offer copay assistance ("patient assistance programs") to publicly insured enrollees with certain health conditions (e.g., multiple sclerosis), provided the manufacturers abide by certain restrictions, including not earmarking their donations specifically for their own medications.
} 
coupons or direct patients to websites or phone numbers to learn more. ${ }^{3}$

Copay coupons (also called "copay cards") may apply to only a subset of a drug's formulations, e.g., the extended release version but not the immediate release version, and may contain caps on the total amount the manufacturer will pay for a given prescription or on behalf of an individual in a given time period. A recent study by Sen et al. (2021) used a proprietary dataset of prescription drug transactions from U.S. pharmacies over 2017-2019 and finds that manufacturer-sponsored "offset" programs, such as coupons, reduce out-of-pocket cost sharing by a median of 87 percent. ${ }^{4}$ Manufacturer offset programs insulate consumers not only from high out-of-pocket spending, but also from price variation across therapeutic substitutes.

\subsection{Multiple Sclerosis}

In the second of our two analyses, we focus on medications to treat multiple sclerosis (MS), a disease characterized by inflammation of the brain and spinal cord. It usually onsets between 20 and 40 years of age and affects over 850,000 individuals in the United States (Wallin et al., 2019). While MS does not usually result in decreased life expectancy, it can cause substantial disability through impacts on sensation and motor, autonomic, and neurocognitive function. MS initially presents in a relapsingremitting form (RR-MS, which accounts for 85-90\% of cases) or a steadily progressing form (primary progressive MS, or PP-MS, which accounts for 10-15\% of cases). In RR-MS, relapses are characterized by one or more new neurological symptoms or a worsening of prior symptoms. ${ }^{5}$

We study the market for drugs called "disease modifying therapies" (DMTs), which are currently the best available treatment for slowing the course of MS. The majority of DMTs (and all of the DMTs that we study) have been approved for treating relapsing forms of MS (RR-MS) and some cases of secondary progressive MS (SP-MS). ${ }^{6}$ DMTs for MS are expensive, and prices have increased significantly over time. Total Medicaid spending on DMTs has increased from $\$ 172$ million in 2008 to $\$ 1.3$ billion in

\footnotetext{
${ }^{3}$ Coupons can be printed by consumers presented at a pharmacy. The pharmacist enters the coupon information as a "secondary insurer," which allows the manufacturer to pay for the coupon users' residual out-of-pocket costs.

${ }^{4}$ The data do not reflect payments made by the charitable foundations described above, as these payments are not made at the point of service.

${ }^{5}$ See Disease-Modifying Therapies for MS, National Multiple Sclerosis Society, 2020. http://www.nationalmssociety.org/NationalMSSociety/media/MSNationalFiles/Brochures/BrochureThe-MS-Disease-Modifying-Medications.pdf

${ }^{6}$ Ibid. DMTs are ineffective for patients with disabilities, patients with PP-MS, and patients with SP-MS without relapses (Lonergan et al., 2009; Torkildsen et al., 2016).
} 
2018 (Elsisi et al., 2020). Using data on individuals covered through both commercial and Medicare Advantage plans, The Health Care Cost Institute estimated spending on DMTs per person diagnosed with MS increased from $\$ 9,400$ per year to nearly $\$ 21,000$ per year between 2009 and 2015. ${ }^{7}$ Both sources find that increases in the list price of DMTs were the largest component of cost increases. While neither study was able to adjust for rebates, a study performed by the Massachusetts Attorney General's office used subpoena authority to obtain rebate information and concluded that net-of-rebate prices for DMTs nearly doubled between 2011 and 2015, from approximately $\$ 3000$ to $\$ 5-6000$ per month. ${ }^{8}$ Consistent with these high prices, up to $75 \%$ of commercially insured MS patients use coupons when they are available. ${ }^{9}$ In sum, DMTs for multiple sclerosis are very expensive and becoming more so, and patients utilizing these medications rely heavily on copay coupons and assistance programs.

\subsection{Related Literature}

As noted earlier, this study builds on a small set of prior studies of copay coupons. Dafny et al. (2017) find that copay coupons increase branded drug sales by over $60 \%$ at the expense of newly released bioequivalent generics. That is, coupons for multi-source brands shift spending toward the branded version without increasing total utilization of the molecule. Lee (2020) predicts that a coupon for a popular statin (Zocor) would drive higher prices and spending. Finally, (Jordan et al., 2020) find that, for singlesource drugs, coupon users are less likely to abandon prescriptions even conditional on the same eventual out-of-pocket price (suggesting that coupons confer "transaction utility" or an advertising effect).

Our paper extends this work by evaluating the causal effect of coupons on singlesource branded drugs. This is an important distinction: while branded drugs overall account for almost $80 \%$ of U.S. prescription drug spending (Hartman et al., 2020), single-source brands account for the vast majority of this spending (in our PBM data, $85 \%$ of branded drug spending is from single-source brands). Moreover, coupons may have a greater impact on the total volume of sales for a single-source drug, as consumers lack access to an inexpensive bioequivalent substitute. Also, while Dafny et al. (2017) did not find an increase in aggregate molecule-level demand as a result of coupons,

\footnotetext{
${ }^{7}$ The Rising Cost of Specialty Drugs Drove Spending Increases for People with Multiple Sclerosis, Health Care Cost Institute Issue Brief, 2018.

${ }^{8}$ Examination of Health Care Cost Trends and Cost Drivers Pursuant to G.L. c. 12C, §17, Commonwealth of Massachusetts Office of the Attorney General, October 7, 2016.

${ }^{9}$ See Starner et al. (2014)'s analysis of pharmacy claims data and Appendix Section B.6 for details.
} 
coupons for single-source drugs may result in both share shifts (i.e., business-stealing among therapeutic substitutes) as well as market expansion.

Our paper is also related to the previous industrial organization literature that models price negotiations in vertical settings. Our simulations apply the Nash-in-Nash model of price negotiations that has been extensively used in previous empirical work studying drug pricing (e.g., Grennan et al. (2022); Tunçel (2020)), insurer-hospital negotiations (e.g. Gowrisankaran et al. (2015); Ho and Lee (2017)), negotiations between hospitals and device manufacturers (Grennan (2013)), and also in non-health care settings (Draganska et al. (2010); Crawford and Yurukoglu (2012)).

\section{Difference-in-Differences Analysis}

\section{$2.1 \quad$ Data Sources}

Drug Coupon Data We construct a dataset spanning 2009 through 2018 using historical snapshots of three online databases of drug coupons: InternetDrugCoupons.com, RxPharmacyCoupons, and NeedyMeds.org. ${ }^{10}$ No single source is available and reliable for the entire time period; see Appendix Section A for details. The unit of observation is the drug name, where drug names reflect those appearing on coupons (e.g., Effexor and the extended release version, Effexor XR, are unique observations). Coupons may become available prior to being posted on the websites, or there may be gaps in the data during which snapshots are unavailable. For these reasons, we record the earliest date a copay coupon is observed on any of the sites for any given drug. For the subset of drugs we ultimately include in our estimation sample, we manually verified coupon dates using historical snapshots of manufacturer websites as well as press releases. For example, we reviewed press announcements of drugs newly approved by the FDA; these announcements often explicitly mention the availability of a coupon, which is evidence the drug was couponed at the time of introduction. ${ }^{11}$ Appendix Section A contains additional details on the coupon dataset. Appendix Section B.1 describes our process for harmonizing drug names across sites and over time, and Appendix Section B.2 provides additional details on the manual verification process.

\footnotetext{
${ }^{10}$ Historical snapshots of the three websites were scraped from https://web.archive.org/

${ }^{11}$ In general, we find that prior to these manual checks, the drug coupon database captures coupons with a median lag of 10 months. We do not assemble data on when/whether coupons are withdrawn. Our understanding is that coupon withdrawal for branded drugs is rare, although it may occur particularly when a drug manufacturer is seeking to shift users of one formulation toward another. Unfortunately, identifying coupon removal is very difficult. We revisit this issue in our analysis of multiple sclerosis drugs (see Appendix B.6).
} 
Pharmacy Benefits Manager Data We leverage a proprietary dataset from a large pharmacy benefits manager (PBM) for January 2014 through June 2017. The unit of observation is the NDC9-month-customer segment, where the customer segments are commercial insurance and Medicare Advantage plans. NDC9 codes are highly granular, 9-digit drug codes that identify the drug labeler (typically a manufacturer) and product (a unique combination of strength, dose, and formulation). The data include a field for the common name of the drug, which differs for branded and generic manufacturers of the same molecule, e.g. Lipitor is the branded version of atorvastatin. For each observation, the data include the average net-of-rebate price per day supplied, total days supplied, total out-of-pocket spending, an indicator for whether the drug is a generic, and the major condition treated (out of 101 categories constructed by the PBM). Rebates negotiated by PBMs are closely held, hence the data source masked the actual net-of-rebate prices by multiplying all net prices by an unknown segmentspecific constant. The masking obscures price levels but allows us to study relative prices and price growth over time.

The price data are highly unique as they reflect net-of-rebate prices, whereas most pharmaceutical research has relied on list prices, wholesale acquisition cost (WAC), or allowed amounts from claims data. Recent exceptions are Sood et al. (2020) and Kakani et al. (2020), who make use of rebates for a subset of drugs estimated by a private company, SSR Health. Due to noisy data for injectable drugs, their analysis excludes the majority of MS DMTs we study in our structural analysis. However, the authors generously provided us with their estimated rebates for these drugs, which decline from a share-weighted average of $24 \%$ in 2012 to a low of $7 \%$ in 2014 before rising again to $18 \%$ in 2017 . We make use of these estimates in our stylized model in Section 3.

Additional Data We obtained data on drug approval dates and active pharmaceutical ingredients from FDA databases, for the time period 1939 through October 2018. The unit of observation is the NDC9, which enables us to merge these data directly to the PBM data. Below, we describe how we use the two data sources to identify (1) which drugs are generic and (2) which drugs have generics. Additional details on the FDA data are in Appendix B.3. 


\subsection{Sample Construction and Descriptive Statistics}

In this section, we provide an overview of how we construct our estimation sample and key variables; additional details are in Appendices B.3 and B.4. To construct our estimation sample, we begin by merging together the PBM and FDA data using the NDC9 codes in both, and dropping observations lacking an FDA match. We also dropped drug indications where at least half of the PBM spending for that indication were from NDC9s that do not have a match in the FDA data. In total, these indications account for only $1.6 \%$ of total costs in the PBM data, and include categories like medical supplies and vaccinations. The combined data account for more than 97 percent of total PBM spending in each segment.

We use the combined data to construct two key indicator variables. The indicator is generic takes a value of 1 if a drug was approved through an Abbreviated New Drug Application (ANDA) or is designated as a generic in the PBM data. ${ }^{12}$ For branded drugs (i.e., drugs not defined as generic), we construct the indicator has generic, which takes a value of 1 if a bioequivalent generic is available for that drug at any point during the study period, i.e. by June 2017. We define a bioequivalent generic as an NDC9 code with is generic = 1 and the same active ingredient list, dosage form, dosage strength, route of administration, and extended-release status as its branded counterpart.

We collapse the resulting data to the drug-month-segment level, where drug is defined by the common name included in the PBM data. ${ }^{13}$ Using fuzzy text matching techniques supplemented by manual checks, we merge in the coupon data, creating an indicator for "coupon" that takes a value of 1 beginning in the relevant drug-month in which it is first observed. ${ }^{14}$ Only branded drugs are observed to have coupons.

The merged PBM-FDA-coupon dataset contains 1,854 unique drugs across commercial and Medicare segments. About half of the drugs (906) are branded. Of all spending in the original PBM dataset (and matched to FDA codes), total spending on these branded drugs accounts for 65 and 66 percent of commercial and Medicare Advantage spending, respectively. These figures are net of rebate, hence the share of spending on branded drugs is lower than that reported elsewhere using gross spending

\footnotetext{
${ }^{12}$ One reason these definitions are not equivalent is that so-called "authorized generics" are unbranded but manufactured under NDAs.

${ }^{13}$ Price is constructed as the cost per day supplied by dividing the total cost by the total number of days supplied.

${ }^{14}$ Drugs that do not merge to an observation in the coupon data are assigned a 0 for coupon status throughout the study period.
} 
data. For example, the Health Care Cost Institute reports that in 2017, spending on brands for the under-65 employer-insured population was nearly 76 percent; however they note this figure is gross of any rebates. ${ }^{15}$

In Figure 1, we plot the share of monthly branded spending accounted for by couponed drugs, separately by segment. Because Medicare enrollees are not permitted to redeem coupons, and therefore manufacturers should be less likely to release coupons for drugs primarily targeting Medicare enrollees, we expect to see somewhat lower shares for the Medicare population. ${ }^{16}$ The data reveal this to be the case, although the difference between the two data series narrows substantially by the end of the study period, when coupons are virtually ubiquitous for branded drug spending in both segments (94 percent of commercial, and 92 percent of Medicare).

Appendix Figure A2 also includes a time series labeled "Medicare Part D," obtained by combining our coupon data with annual Medicare Part D spending by drug, limited to the same set of drugs present in our merged PBM-FDA data. For this time series, we use coupon status as of June in the relevant year. The additional time series shows that the share of Part D spending potentially impacted by coupons is similar to that observed for the Medicare segment of our PBM data, suggesting the PBM data are likely to be representative of Medicare spending.

\section{[Figure 1 Here]}

The sharp increases in the couponed share of spending in late 2014 for both the commercial and Medicare segments can mostly be accounted for by the introduction of a coupon for Revlimid, a cancer drug with high spending, the approval of Harvoni for hepatitis $\mathrm{C}^{17}$ and large spending increases for Levemir (a couponed insulin). The subsequent decline in couponed spending share that occurs only in the commercial segment in early 2015 is driven by a concurrent decrease in the spending share of Harvoni and an increase in the spending share of Viekira, a non-couponed alternative.

Our empirical analysis explores the impact of coupons on single-source drugs, so we eliminate branded drugs with generics at any point in the study period, which leaves 589 branded drugs but retains the vast majority of spending: net-of-rebate spending for single-source drugs accounts for 86 percent of branded spending in the

15 2017 Health Care Cost and Utilization Report, Health Care Cost Institute, 2019.

${ }^{16}$ The expectation of different couponed shares assumes (1) different utilization levels across the two segments; and (2) non-trivial cost of introducing a coupon program.

${ }^{17}$ Like many drugs, Harvoni's coupon coincided with its introduction. 
commercial population and 83 percent in the Medicare population. Next, we exclude drugs without utilization in both populations, or which have very different utilization levels in the commercial and Medicare populations (e.g., drugs for attention deficit hyperactivity disorder). Including these drugs may result in a violation of the parallel trends assumption for commercial and Medicare populations absent coupons. Further details on sample construction are provided in Appendix Section B.4.

After applying the utilization restrictions, there are 366 drugs remaining. Of these, 275 are always observed to have a coupon during the study period ("always-couponed"), 35 are not couponed at any point in the study period ("never-couponed"), 56 introduce a coupon during the study period ("switchers"), and 33 of these have a sufficiently long pre- and post-period to be included in our final estimation sample. Table 1 reports the effect of each sample restriction on the number of unique drugs and share of spending remaining after each step. The main reduction in sample occurs when excluding "always couponed" drugs, which account for a significant share of branded spending but do not have a pre-period. Both "always couponed" and "never couponed" drugs are excluded in our primary analysis, which focuses on switchers.

\section{[Table 1 Here]}

Table 2 contains summary statistics for these drugs. The top panel contains aggregate statistics for each category of drugs, including the distribution of total spending across the three coupon categories. Always-couponed drugs account for around 90 percent of spending in both the commercial and Medicare Advantage segments in this sample. Drugs with new coupon introductions during the study period account for 9 percent of spending in each segment, while never-couponed drugs account for less than 2 percent of spending. Switchers in our balanced estimation sample treat a range of conditions, including cancer ( 7 drugs) and eye-related conditions or infections (4 ophthalmic, 2 eye infection, and 1 glaucoma drugs). The full set of indications is reported in Appendix Figures B5 and B6.

The second panel of Table 2 presents drug-level statistics. The average annual list price (obtained from the first year a drug is observed in the Medicare Part D data) is highest for switchers and lowest for never-couponed drugs. ${ }^{18}$ The average compound

\footnotetext{
${ }^{18}$ As previously noted, the PBM data include only a normalized price measure, and the normalization differs by segment, so price levels from the PBM data are uninformative. For this reason we rely on list prices from Medicare Part D for these general summary statistics. The regression analyses below use net-of-rebate prices from the PBM data.
} 
annual growth rate (CAGR) in price is fairly similar across all three groups. There is wide variation in the volume of drug utilization within and across categories, as well as in utilization growth. Average monthly days supplied per always-couponed drug is around 64,000 as compared to 15,000 per switcher and 8,700 per never-couponed drug.

Table 2 also lists the leading medical conditions for drugs included in each category. Diabetes drugs appear frequently in all three groups. HIV drugs, which have very high prices, are common in the "always couponed" group. Taken together, these summary statistics suggests that always-couponed or never-couponed drugs are not ideal control groups for switchers. Hence, our analysis and identification strategy focuses on switchers.

\section{[Table 2 Here]}

\subsection{Empirical Specifications}

To assess the impact of coupon introduction on net-of-rebate prices and quantities, we pursue a difference-in-differences approach, comparing the change in outcomes before vs. after coupon introduction for the treatment group (the commercial segment) with that of the control group (the Medicare segment). The key identifying assumption is that the trends in outcomes absent the coupon would have been similar in the two groups. The ability to include drug-specific control groups (rather than to rely on a simple pre vs. post comparison for the treatment group) is particularly valuable given that coupons may not be exogenously introduced, and may in fact be introduced when price or quantity growth is expected to decline. As long as any time-varying omitted factors impacting utilization or price have a common proportional effect on commercial and Medicare enrollees, the differences-in-differences estimate will capture the shortterm effect of coupons. In addition, having a calendar-time-matched control for each treatment unit eliminates bias that can arise from heterogeneous treatment effects and staggered treatments (Borusyak et al., 2021; Sun and Abraham, 2021; GoodmanBacon, 2021; Callaway and Sant'Anna, 2020). Our estimator is akin to a "stacked" design, which is often used to surmount such biases; effectively, we recover an average of drug-specific commercial vs. Medicare differences in responses to a coupon (Baker et al., 2022).

We expect the estimates to be conservative, however, as Medicare enrollees may utilize patient assistance programs which, while not drug-specific, may be contemporaneously introduced or expanded for the same reasons underlying a coupon introduction. 
We estimate the following specification using observations at the drug-month-segment level:

$$
\begin{aligned}
Y_{j k t} & =\sum_{q \in\{-3,3\} \backslash-1} \gamma_{q} \mathbf{1}(\text { quarter }=q) \cdot \mathbf{1}(\text { commercial })_{k} \\
& +\sum_{q \in\{-3,3\} \backslash-1} \eta_{q} \mathbf{1}(\text { quarter }=q)+\alpha_{j k}+\delta_{j t}+\varepsilon_{j t k}
\end{aligned}
$$

where $Y_{j t k}$ is either $\log$ quantity (defined as the number of days supplied) or log net-of-rebate price for drug $j$ in period $t$ and segment $k$. The data are monthly, with $t$ reflecting each month from January 2014 through June 2017. The variable quarter denotes the number of quarters before or after coupon introduction, with quarter $=0$ for the first 3 months a coupon exists for drug $j \cdot \gamma_{q}$ are the coefficients of interest: they capture the difference in outcomes in the commercial segment relative to Medicare before and after coupon introduction. The $\eta_{q}$ coefficients capture common changes in $Y_{j t k}$ leading up to, and following coupon introductions. (We use quarters rather than months to gain precision in our estimates of interest, and because there is some uncertainty around the exact timing of coupon introduction.) The $\alpha_{j k}$ and $\delta_{j t}$ coefficients denote drug-segment and drug-year-month fixed effects. The former control for time-invariant differences within drugs across segments, and the latter allow us to flexibly control for drug-specific trends in outcomes, using the Medicare segment for each drug as a drug-specific control group. The results are very similar if we include year and month fixed effects in place of year-month fixed effects, or if we use year-month fixed effects instead of drug-year-month fixed effects. For parsimony, we present specifications with drug-year-month effects. We cluster standard errors at the drug level.

The estimation sample includes drugs denoted as "switchers" in Table 2 above, restricted to those observed at least 9 months before and after the quarter of coupon introduction. The panel is balanced so each drug is included for 21 months in total, although the calendar months vary across drugs. Descriptive statistics for this sample are included in Column 4 of Table 2.

\subsection{Results}

Table 3 presents the coefficients of interest from estimating equation (1) on the balanced switchers sample, using either logged quantity (Columns 1-2) or logged price (Columns 3-4) as the dependent variable. We estimate equation (1) by unweighted and weighted 
OLS, weighting each observation by the share of within-segment spending accounted for by the relevant drug in the 6 months prior to coupon introduction. ${ }^{19}$ The weighted specifications (Columns 2 and 4) may better represent the average impact of coupons on spending, as coupon effects for drugs that account for a larger share of total spending receive more weight.

Figure 2 plots the corresponding estimated coefficients from the unweighted and weighted models, with results for quantity in the top panel and price in the bottom panel. The figure plots the point estimates and 95\% confidence intervals for the quarterly interaction terms with the commercial segment indicator (i.e., $\hat{\gamma}_{q}$ ) in equation 1 above). ${ }^{20}$ The figures confirm that for three of the four specifications, there is no differential trend in quantity or price for commercial relative to Medicare enrollees in the quarters prior to coupon introduction. There is a modest increase in relative price for commercial enrollees ( 2 percent) in the 3 quarters preceding coupon introduction in the weighted model (Figure 2 panel $\mathrm{d}$ ). In this case, the parallel trends assumption may not be satisfied. A linear extrapolation of the pre-trend might suggest that commercial prices are growing slower in the post-period than in the pre-period (Rambachan and Roth, 2023). However, given the differences between weighted and unweighted specifications and large standard errors, the analysis in Figure 2 provides limited evidence on the short-run effect of coupons on price. $^{21}$

The quantity graphs show clear and large increases in quantity beginning in the second quarter after coupon introduction (i.e., months 4-6 after the month of introduction). The magnitude of the quantity effect increases over time, perhaps due to coupon introductions that occur mid-year and affect demand in the following year as deductibles and out-of-pocket maximums reset. Both the unweighted and weighted specifications imply increases in the relative quantity of couponed drugs used in the commercial segment of 23-25 percent by the third quarter after coupon introduction; coefficient estimates are reported in Table 3. The relative similarity of the results for

\footnotetext{
${ }^{19}$ The masking procedure applied by the PBM data source affects relative spending between segments. To account for this, we normalize the average weight across drugs to be the same for Medicare and commercial segments.

${ }^{20}$ To assess the effect of having a small number of $N=33$ clusters, we also construct $95 \%$ confidence intervals using the cluster wild bootstrap procedure, which produces very similar results. See Appendix Section C.2 for results.

${ }^{21}$ Appendix Section C.3 reports versions of this specification where the coefficients of interest are estimated at the monthly level, to better visualize the pre-trends and dynamic effects at the expense of a modest increase in the standard errors. Our conclusions regarding pre-trends and effect estimates are unchanged.
} 
weighted and unweighted models suggests similar responses across drugs with different revenue levels.

To determine whether this quantity effect is driven by increases in commercial utilization, decreases in Medicare utilization, or both, we estimate specifications that include separate quarter interactions for each segment. This illuminates absolute changes in segment-specific quantity for newly couponed drugs. The results show that demand for newly couponed drugs is increasing in both segments prior to coupon introduction, but post-introduction demand surges upward only for the commercially insured population (see Appendix C.1 for more details).

[Table 3 Here]

[Figure 2 Here]

In contrast, the price specifications do not show post-coupon increases in net-ofrebate prices for drugs supplied to the commercial versus the Medicare population. The lack of a price response may be due to the fact that list prices are common to all segments, so that changes in price for a specific segment would require changes in segment-specific rebate arrangements with the PBM. While the source of PBM data reports that segment-specific rebates do occur, so that manufacturers could attempt to negotiate lower rebates for the commercial sector after introducing a coupon-or propose smaller increases in rebates for the commercial sector as compared to the Medicare sector-we do not find evidence of such renegotiations within the 12 months following a coupon introduction. This is perhaps unsurprising given that rebates are typically negotiated once per year.

\subsection{Robustness and Extensions}

As a robustness check, we re-estimate both the weighted and unweighted regressions for quantity responses, dropping drugs from our sample one at a time, and pooling the post-coupon period into a single indicator variable. The pooled quantity effect for the full 33-drug sample is $16.6 \%$ for the unweighted specification and $17.7 \%$ for the weighted specification. ${ }^{22}$ The unweighted estimates obtained when dropping one drug at a time all lie between $14.8 \%$ and $18.7 \%$ with similar standard errors. With the exception of dropping Revlimid (an oral chemotherapy approved to treat various blood

\footnotetext{
${ }^{22}$ While the specification with a pooled post-period is convenient for performing robustness checks, our preferred specification is equation (1), which disaggregates the post period into quarters. Coupon effects are likely to build over time, at least within the year after introduction.
} 
cancers), the weighted estimates all lie between $15.2 \%$ and 18.9\%. Dropping Revlimid, a high-revenue coupon-switcher drug, leads to a slightly smaller weighted estimate of 14.3\%. The full distributions of pooled effects (dropping one drug at a time) are shown in Figure 3 below.

[Figure 3 Here]

We also estimated models that attempted to discern whether the coupon-induced utilization growth arises primarily from market expansion or from "business stealing" by newly couponed drugs. However, due to significant difficulties in identifying therapeutic substitutes for all 33 index drugs, as well as the fact that many couponed drugs accounted for a very small share of their respective drug markets (as defined using drug-level data), the effort was not fruitful. See Appendix C.7 for details.

External Validity Our estimation sample $(\mathrm{N}=33)$ includes only $10 \%$ of all singlesource branded drugs with coupons. We therefore perform additional analyses to assess whether the results are likely to generalize to the wider set of all single-source branded drugs with coupons. First, we estimate our main specification using an unbalanced panel of all $\mathrm{N}=56$ switchers (corresponding to Column 3 of Table 2). The results were very similar, suggesting that coupon effects for switchers without adequate pre- and post-periods are similar (see Appendix Section C.4 for details).

Next, we perform an analysis to quantify the potential coupon effect for drugs that are already couponed when they enter the market. Because these drugs lack a precoupon period, we cannot apply our main difference-in-differences approach. Instead, we compare the difference in quantities for the commercial vs. Medicare segments for always-couponed drugs with the same difference for never-couponed drugs. To the extent that coupons are associated with a boost in commercial volume, we expect the difference in these differences to be positive. We find this is indeed the case: alwayscouponed utilization among the commercially insured sample relative to the Medicare sample is twice that of never-couponed drugs. For details and tables, see Appendix Section C.5. This finding is consistent with the result from the switchers analysis, and suggests that those results may be conservative. However, because the decision to introduce a coupon at launch may not be exogenous to the expected success of the drug for the commercial vs. Medicare population, this analysis is suggestive rather than definitive. 
To give additional context regarding the external validity of our estimates, we compared the indications treated by the drugs in the balanced estimation sample $(\mathrm{N}=33)$, unbalanced estimation sample $(\mathrm{N}=56)$, and always-couponed drugs $(\mathrm{N}=275)$; see Appendix Figure B5. The figure shows the indications treated by drugs in our estimation samples (especially the unbalanced sample) are generally similar to those treated by always-couponed drugs. The main differences are that our estimation sample includes more drugs that treat cancer, eye and skin conditions, seizures, and erectile dysfunction, and fewer drugs that treat diabetes, HIV, and psychiatric/neurologic disorders drugs that tend to be always couponed in our data. In the next section, we consider the evidence for heterogeneity in coupon effects across a range of drug characteristics, including the indication treated.

Heterogeneity in Coupon Effects To assess whether certain types of drugs exhibit larger coupon effects than others, we re-estimated specification 1 in the text, adding additional interaction terms between the post-period quarters and an indicator for different groups. We summarize the findings here; Appendix Section C.6 contains additional discussion and graphs of the coefficient estimates.

We first consider whether drugs with above-median commercial market shares (relative to Medicare) have differential responses to coupons. ${ }^{23}$ We find smaller estimated coupon effects for drugs with larger commercial market shares, which we hypothesize is due to spillover effects of coupons on Medicare demand for these drugs. Consistent with this hypothesis, we find that among drugs with above-median commercial market share, both Medicare and commercial quantities increase following coupon introduction, whereas among drugs with below-median commercial market share, only commercial quantities increase (see Appendix Figure C14).

Second, we find coupon effects vary by drug indication. In our sample, the effects are largest for drugs treating cancer or eye conditions. We considered other potential sources of heterogeneous effects, including price levels and the degree of patient costsharing (as a percent of drug price). We find suggestive evidence that coupon effects are larger among higher-priced drugs, but cannot separately identify this effect from the large effect of cancer drugs, which are all high-priced. We do not find statistically significant heterogeneity by degree of cost sharing.

\footnotetext{
${ }^{23}$ Commercial market share for each drug is defined as the average pre-period spending in the commercial segment divided by the average pre-period spending in the Medicare segment.
} 


\subsection{Summary of Difference-in-Differences Analysis and Ratio- nale for Model}

In sum, the reduced-form analysis of coupon introductions suggests that coupons can induce a sizeable increase in the volume of prescription drugs sold, consistent with studies showing a high elasticity of consumer demand for prescription drugs with respect to out-of-pocket cost-sharing. However, our estimates are based on a somewhat small and selected sample of drugs, specifically those that do not introduce a coupon when they are launched and for which we observe a 9-month pre-period and 12-month post-period.

The reduced-form analysis leaves some open questions that benefit from the additional structure we impose in the following sections. In particular, we do not find evidence that coupons are associated with relative price changes; however, that analysis is not well-suited to estimating the price effects of coupons. List prices do not vary across segments, and rebates (which can differ across segments) may take more time to adjust than we observe in our short post-coupon study period. Also, the effects of individual coupon introductions may differ from the equilibrium effects of a policy banning on all coupons. To obtain predictions of how equilibrium prices are affected by the ability of manufacturers to offer coupons, we turn to our detailed analysis of one market in particular: disease-modifying therapies (DMTs) for MS.

\section{Model for Estimation}

In this section, we describe our framework for modeling the equilibrium effect of coupons. As compared to the reduced form analysis, this model enables us to evaluate the effects of multiple coupons on both couponed drugs and their competitors. We use it to simulate the impact of a general coupon ban on drug choice and prices for all options in patients' choice sets. As we explain in the next section, we are unable to allow for market expansion, so that the total quantity of MS drugs purchased is assumed to be unchanged when coupon availability changes. Therefore, this analysis provides an estimate of the price effect of coupons, complementing the estimate of the quantity effect of coupons from the reduced-form analysis.

We estimate a model of demand and parameterize a model of supply that enables us to quantify the extent to which the optimal price (pooled across both segments) is likely to change in the presence of coupons. While we have limited data on the supply side of the market, we make use of detailed claims data to estimate demand and include terms 
in the demand model to measure the effect of coupons. The estimates are a crucial input into our simulated model of net price determination.

We assume that, prior to the stages we model, insurers set coinsurance and copays, consumers decide which insurance plans to purchase, and drug manufacturers make decisions about whether to offer coupons. Insurers are responsible both for non-drug benefits and for drug benefits, which may be outsourced to a PBM. We assume that all coupons fully offset consumer cost-sharing. Because we do not observe plan formularies, we assume that no drugs are excluded from any formulary in equilibrium; ${ }^{24}$ however, the threat of exclusion impacts negotiated prices. Taking these attributes as predetermined, a model of price-setting and demand in this market has the following stages:

1. Drug manufacturers choose list prices and negotiate rebates with insurers

2. Insurers set premiums for the following year

3. Consumers choose a drug from the set of options available for their diagnosis. A subset of consumers redeem a coupon for their purchase.

We allow coupons to increase demand in two ways. First, they directly reduce the out-of-pocket prices of patients who use them. Second, coupons may have a nonprice, "advertising effect" on all individuals, regardless of whether they actually redeem a coupon. ${ }^{25}$ In particular, physicians may be aware that a drug is couponed - as sales representatives typically advise them of this fact and may share coupon cards to distribute - and the knowledge that a drug can be obtained at a low out-of-pocket cost may increase the likelihood that a physician prescribes it and therefore gains experience with the drug. This increased propensity to prescribe couponed drugs may therefore impact all of the physician's patients, even those who do not ultimately use coupons.

\footnotetext{
${ }^{24}$ Note that the drug-year fixed effects do account for differences in formulary exclusion across drugs and over time, and the drug-segment fixed effects account for time-invariant, drug-specific differences across segments. To further evaluate the assumption of complete formularies, we manually collect MS drug coverage data from formularies of insurers included in the HCCI data. The data suggest a high overall coverage rate for MS drugs of 87\%. See Appendix Section D.1 for details.

${ }^{25}$ Our empirical analysis allows for the non-price/advertising effect of coupons to differ across Medicare and commercial enrollees. The effect for Medicare enrollees is captured through the coupon indicator, which applies to both market segments and also addresses the potential endogeneity of coupon introduction, which may occur in response to demand shocks. Our focus in the model is on the incremental advertising effect for commercial enrollees.
} 
Both demand effects are likely to exert upward pressure on drug prices and premiums. ${ }^{26}$ However, there are offsetting effects, largely due to the impact of negotiations with insurers, that make both the magnitude and the direction of the overall price effect of coupons theoretically ambiguous. ${ }^{27}$

Our model is designed to tease out these effects and allow us to quantify the impact of coupons on prices and spending in equilibrium. The model relies on a number of simplifying assumptions necessitated by data constraints. First, we assume that consumer selection into plans takes place in an initial step before our model begins: that is, consumers do not switch plans based on changes in out-of-pocket drug prices or the impact of drug price changes on premiums. ${ }^{28}$ Second, we assume insurance plan markups and non-pharmaceutical costs are invariant to the introduction of coupons. Third, we combine the setting of list prices and negotiation over rebates into a single step in which the insurer and manufacturer negotiate over net-of-rebate price.

In the following subsections, we work through the stages of the model in reverse order. We begin with a model of drug demand (Stage 3), then specify how insurers set premiums (Stage 2), and finally show how net-of-rebate prices are determined in a model of insurer-manufacturer negotiations (Stage 1). We use the resulting model to clarify the mechanisms through which coupons affect prices. Then we combine our demand estimates with the pricing model to conduct counterfactual simulations that show how prices change when coupons are banned. We present our demand estimates in Section 4 and simulation results in Section 5.

\footnotetext{
${ }^{26}$ It is possible that, by attracting new consumers through the advertising effect, coupons could increase the price elasticity of the marginal consumer and hence reduce the optimal markup. This seems unlikely, particularly in our setting where all diagnosed patients are assumed to take a drug. ${ }^{27}$ Corts (1998) shows that, even without price bargaining, coupons may generate either lower or higher list prices because they allow firms to price discriminate, sorting customers into multiple groups, only some of which use coupons. If consumer preferences across firms are not symmetric then coupons can generate reduced list prices for some firms.

${ }^{28}$ This assumption is plausible for enrollees in employer-sponsored health insurance, as employers typically offer a limited selection of plans. Even when multiple plans are offered, they often utilize the same PBM and hence the same drug benefit design (i.e., set of drugs that are covered and copay tier associated with each), so that their enrollees effectively have a single option for drug insurance. For Medicare enrollees, plan switching is uncommon: a prior literature argues that enrollees rarely switch between Part D plans, in part because of inattention regarding changes in plan coverage and premiums. See, for example, Ho et al. (2017).
} 


\subsection{Drug Demand}

We model each consumer's choice of drug as a discrete choice among options available to treat a particular condition. ${ }^{29}$ This choice varies based on individual characteristics, including the individual's insurance segment (i.e., commercial or Medicare Advantage). Medicare enrollees are prohibited from utilizing coupons, however as previously noted we allow for the possibility that their choices are affected by an "advertising effect" of coupons. The utility of a Medicare Advantage enrollee $i$ choosing drug $j$ in year $t$ can be written:

$$
u_{i j t}^{M A}=\delta_{j t}+\gamma \operatorname{coupon}_{j t}+\alpha p_{i j t}^{O O P}+X_{i j t}^{\prime} \beta+\varepsilon_{i j t}
$$

where drug-year fixed effects $\delta_{j t}$ allow the mean utility of each drug to vary flexibly over

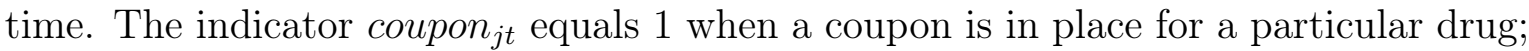
$\gamma$ measures the change in utility upon coupon introduction for Medicare Advantage enrollees. It combines the effect of any within-year demand shocks that coincide with coupon introduction ${ }^{30}$ with potential advertising effects of coupons for these enrollees. It is common for all couponed drugs and time periods. Out-of-pocket prices $p_{i j t}^{O O P}$ depend on consumers' coinsurance rates or copay amounts. The variables $X_{i j t}$ denote drug time-since-approval bins and their interactions with gender, which capture the ramp-up of each drug's sales in the months after its introduction. ${ }^{31}$ The error term $\varepsilon_{i j t}$ is distributed Type 1 extreme value.

We assume that there are two types of commercially insured consumers. With probability $\lambda$ a particular consumer will redeem coupons for drug purchases and face a zero out-of-pocket price, ${ }^{32}$ while with probability $1-\lambda$ she does not use them. As in the utility specification for Medicare Advantage enrollees, we allow for the possibility

\footnotetext{
${ }^{29}$ Appendix Section B.6 details how we constructed our demand estimation sample using the HCCI data.

${ }^{30}$ While the reduced form analysis suggests that coupons are not, on average, introduced to coincide with negative demand shocks, we still allow for the possibility in this particular sample of drugs.

${ }^{31}$ We define drug age as the time since FDA approval. To capture the non-linear increase in adoption of a drug over time, we specify the time since FDA approval using indicators for under 6 months (omitted category), 6-12 months, 1-2 years, 2-3 years, 3-5 years, and $5+$ years. We find adoption trends vary by gender, hence we include gender interactions. The results are insensitive to the inclusion of these terms.

${ }^{32}$ In practice, some coupons only reduce out-of-pocket prices to a fixed residual amount (e.g., $\left.\$ 10\right)$, which declines over time to $\$ 0$ for all coupons by the end of our sample. A minority of coupons also have limits placed on the costs they cover. In Appendix Section E.2, we show that using quantitative coupon amounts has little to no effect on our results.
} 
that coupons boost demand independently of their impact on out-of-pocket price, and that the magnitude of this "advertising effect" may differ across the two segments. ${ }^{33}$ The utility specification for commercially insured consumer $i$ who chooses $\operatorname{drug} j$ in year $t$ is therefore

$$
u_{i j t}^{c o m}= \begin{cases}u_{i j t}^{c}=\delta_{j}^{c o m}+\delta_{j t}+\left(\gamma+\gamma^{c o m}\right) \operatorname{coupon}_{j t}+X_{i j t}^{\prime} \beta+\varepsilon_{i j t} & \text { with proba. } \lambda \\ u_{i j t}^{n c}=\delta_{j}^{c o m}+\delta_{j t}+\left(\alpha+\alpha^{c o m}\right) p_{i j t}^{O O P}+\left(\gamma+\gamma^{c o m}\right) \operatorname{coupon}_{j t}+X_{i j t}^{\prime} \beta+\varepsilon_{i j t} & \text { with proba. } 1-\lambda\end{cases}
$$

where $\delta_{j}^{c o m}$ allows the mean utility of each drug to vary by segment; this captures any fixed differences in drug preferences between segments. The parameters $\gamma^{\text {com }}$ and $\alpha^{\text {com }}$ allow the coupon advertising effect and the effect of price to differ between commercial and Medicare Advantage enrollees.

In practice, since we do not observe coupon usage at the individual or drug level, we fix $\lambda=0.75$ based on estimates of coupon utilization for MS drugs reported in Starner et al. (2014) and estimate the remaining parameters of equations (2) and (3) jointly by maximum likelihood. Appendix Section D.1 provides additional details, including the likelihood function, and Appendix Section E.2 discusses alternative assumptions for $\lambda$, including allowing it to vary by patient cost-sharing. We assume that every diagnosed consumer chooses a drug, i.e., there is no outside option in this specification. This assumption is necessary because we do not reliably observe patients with MS who never take a drug, as an MS diagnosis without an associated medication claim may not appear in our claims data. Moreover, we do not observe the timing of individuals' decisions to forgo any MS drug. Thus, our analysis does not allow for market expansion effects of coupons.

\subsection{Insurance Premiums}

The average premium for a plan in segment $k$ and period $t$ is the marginal cost per enrollee plus a markup. ${ }^{34}$ We simplify the true premium-setting model by assuming that

\footnotetext{
${ }^{33}$ We also test alternative specifications where the commercial advertising effect is larger for coupon users, which may reflect the scenario where the advertising effect and coupon usage are both linked to knowledge of a coupon's existence. See Appendix Section E.2 for details.

${ }^{34}$ The average premium can be written as: $\frac{1}{N_{k t}^{I}} \sum_{i \in I_{k t}}\left[\mu_{i k t}+\omega_{i k t}+\sum_{j \in J_{t}} s_{i j k t}\left[p_{j t}-p_{i j k t}^{O O P}\right]\right]$ where $N_{k, t}^{I}$ is the total number of enrollees in segment $k$ and year $t$ and $I_{k, t}$ is that set of enrollees, $\mu_{i k t}$ is the markup for consumer $i$ (measured in dollars) which might vary across consumers and across plans, $\omega_{i k t}$ is the insurance plan's non-drug cost of enrolling that consumer, $s_{i j k t}$ is the probability that patient $i$ chooses drug $j$ (determined by the demand model outlined above), and $p_{j t}$ is the negotiated net-of-rebate price for $\operatorname{drug} j$. Our simulations normalize $\omega_{i k t}$ and $\mu_{i k t}$ to zero.
} 
the insurer markup and non-pharmaceutical costs are unaffected by the introduction of coupons and can be held fixed in our simulations. We normalize them to zero and consider the component of premiums that covers the insurer's drug costs.

\subsection{Drug Pricing}

We use a simple framework that assumes drug manufacturers and insurers engage in Nash-in-Nash bargaining over net-of-rebate prices, rather than separately modeling the determination of manufacturer list prices and the negotiation of rebates with the relevant insurer. ${ }^{35}$ The impact of coupons on net-of-rebate prices that is predicted by our model reflects both effects on list prices and on rebates. This approach also accounts for sources of insurer leverage that would be difficult to capture in the more fully specified model, including prior authorization, hassle costs, and/or threats to alter copay and coinsurance rates in response to very high list prices. ${ }^{36}$

Consumer Cost-Sharing To compute consumer out-of-pocket prices, we need to recover the list price separately from the net-of-rebate price. We do so by applying a rebate percentage from an external data source. In our counterfactual simulations, we explore robustness to different rebate rates and alternative assumptions over whether and how much rebates adjust when coupons are removed.

Cost-sharing in our setting takes the form of a percentage coinsurance rate or a fixed copay. If the consumer pays a coinsurance rate $\rho_{i}$, she pays a fixed percentage of the list price, so the out-of-pocket price is $p_{i j k t}^{O O P}=\rho_{i} p_{j t} /\left(1-r_{j t}\right)$ where $p_{j t}$ is the net-of-rebate price and $r_{j t}$ is the rebate percentage. Other consumers pay a fixed copay, which we assume is invariant to changes in list prices. As previously noted, we assume that consumers who use coupons have zero out-of-pocket costs. ${ }^{37}$ Only the minority of enrollees who face a coinsurance rate actually pay a portion of the negotiated price.

\footnotetext{
${ }^{35} \mathrm{~A}$ full model of drug pricing would distinguish between these two components: list prices-which manufacturers set - and rebates, which manufacturers negotiate with insurers and which may depend on the formulary placement of each drug relative to its substitutes. The manufacturer's payment (the net-of-rebate price) is the list price after applying the negotiated rebate rate. Because we lack insurer identifiers and information on each drug's formulary placement, we do not develop and estimate such a model.

${ }^{36}$ Note that this last channel is also impacted by coupons: insurer responses that threaten to increase cost sharing are weakened by the existence of coupons. Because we do not include this insurer response in our model, our simulations may understate the impacts of coupons.

${ }^{37}$ The impact of a change in the net-of-rebate price on the out-of-pocket price paid by the consumer, $\frac{\partial p_{i j t}^{O O P}}{\partial p_{j t}}$ is therefore given by $\rho_{i} /\left(1-r_{j t}\right)$ if the plan uses coinsurance rate $\rho_{i}$ and no coupon is used, and 0 if $j$ has a coupon and $i$ uses coupons or if the plan uses copays.
} 
Coupon introduction reduces this proportion of enrollees still further, leading to upward pressure on prices.

Manufacturer-Insurer Price Negotiations We assume that the net-of-rebate price of every drug, $p_{j t}$, is determined via simultaneous bilateral Nash bargaining between the manufacturer and insurer. Given our limited data, we simplify by assuming that a single insurer covers the entire market through an array of plans, and that all branded MS drugs are included on its formulary in equilibrium. A single price for a particular drug applies jointly to both commercial and Medicare Advantage markets.

We make the common assumption (e.g., Capps et al. (2003), Gowrisankaran et al. (2015)) that our single insurer maximizes consumer surplus (net of consumer costsharing for drugs) less total pharmaceutical costs. ${ }^{38}$ The insurer's objective function is then:

$$
V\left(J_{t}, p_{t}\right)=C S\left(J_{t}, p_{t}\right)-T C\left(J_{t}, p_{t}\right)
$$

where $J_{t}$ is the complete set of MS drugs available to enrollees from all manufacturers at time $t, p_{t}$ is the vector of their net-of-rebate prices, $C S(\cdot)$ denotes consumer surplus and $T C(\cdot)$ denotes total drug costs. ${ }^{39}$ Both consumer surplus and total costs depend critically on the predicted drug choices of both commercial and Medicare Advantage enrollees as a function of prices and coupon availability, obtained from the demand model. Details are provided in Appendix Section D.2.

The manufacturer's objective function is its profit:

$$
\pi_{j, t}\left(p_{j, t}\right)=\sum_{k} \sum_{i \in I_{k, t}} s_{i j k t}\left(p_{j t}-c_{j t}\right)-\lambda \operatorname{coupon}_{j, t} \sum_{i \in I_{\text {com }, t}} s_{i j t}^{c} p_{i j t}^{O O P}
$$

where $I_{k, t}$ denotes the enrolled population for segment $k$ in period $t, c_{j t}$ is the manufacturer's marginal production cost for drug $j$ in period $t$, and the last term reflects the additional cost to the manufacturer (of a couponed drug) from paying the out-of-pocket costs of commercially insured individuals who redeem coupons.

\footnotetext{
${ }^{38}$ We are implicitly assuming that the insurer values patient surplus 1:1 with costs. We test alternative weights in Appendix Section E.2

${ }^{39}$ Our measure of consumer surplus accounts for consumer out-of-pocket payments but does not include premiums paid. We account for the disutility from high premiums by including insurer total costs in the objective function.
} 
The negotiated price for product $j$ maximizes the Nash product:

$$
p_{j, t}=\arg \max _{p}\left(\pi_{j, t}(p)\right)^{\eta}\left(V\left(J_{t}, p\right)-V\left(J_{t} \backslash j, p\right)\right)^{1-\eta}
$$

where $\eta$ is the Nash bargaining parameter (assumed constant across all manufacturers).

In the Appendix, we derive expressions for negotiated prices both with and without the existence of coupons. It is clear from comparing the two expressions that the net effect of coupons on predicted negotiated prices is an empirical question.

\section{Demand Estimation}

We use claims data from the Health Care Cost Institute (HCCI) to derive individuallevel drug choices from 2009 through 2017, comparing individuals just above vs. below the age threshold for Medicare eligibility. We focus on the market for multiple sclerosis (MS) drugs. In particular, we restrict to choices over disease-modifying therapies (DMTs), believed by experts to be the best strategy currently available for slowing the natural progression of MS. We focus on this set of drugs because the choice set is well-defined, there is a good deal of coupon variation, and there are no generic versions of most of these drugs during our sample period (just one enters in 2015, and it was not competitively priced). Generic drugs can have significant impacts on market shares of therapeutic substitutes, so the limited role of generics in this segment during our study period helps to isolate coupon effects. Further, DMTs for MS are costly specialty medications: the DMTs that we study account for $0.058 \%$ of all prescriptions but $4.6 \%$ of the total prescription drug costs in the HCCI data. Over the course of our study period, eleven DMTs are offered. Two of the DMTs introduce a coupon during our sample period, five are never couponed during our sample period, and the remaining drugs are always observed with a coupon. Details of the data, our method to infer outof-pocket prices, and our sample selection criteria are provided in Appendix Section B.6.

Table 4 shows descriptive statistics for the estimation sample. From 2009 to 2017, average allowed amounts (our measure of list prices) increased substantially for all drugs in the choice set, from about $\$ 3,000$ in $2009-2011$ to about $\$ 6,000$ in $2015-2017$. Outof-pocket costs also approximately doubled over the same period, averaging about $\$ 250$ per prescription for commercially insured patients and $\$ 550$ for Medicare Advantage enrollees in 2015-2017. 
[Table 4 Here]

\subsection{Demand Estimation Results}

We estimate three specifications and present the results in Table 5. Our preferred specification (Column 3 of Table 5) includes drug-by-year fixed effects, which allow preferences for each drug to vary flexibly over time, and drug-segment fixed effects, which allow commercially insured patients to systematically prefer different drugs than Medicare patients. Thus, identifying variation in our main specification primarily comes from drugs that we can observe before and after they introduce a coupon. Changes in the choice set when new drugs are introduced, with or without coupons, also generate useful variation.

Our second demand specification (Column 2 of Table 5) omits drug-segment fixed effects, allowing identifying variation for the estimated coupon effect to come from comparisons of always- vs. never-couponed drugs across segments. Medicare enrollees cannot redeem coupons, so greater attractiveness of a couponed drug for commercial enrollees just below the Medicare age threshold would - in this specification - contribute to a positive estimated effect of coupons on demand. Our last specification (Column 1 of Table 5) omits both drug-segment fixed effects and the $X_{i j t}$ terms, which are the drug time-since-approval bins and their interactions with gender.

The drug-year and drug-segment fixed effects in our preferred specification also absorb demand shocks that could confound our estimates of the price coefficient. We estimate a price coefficient using variation in out-of-pocket prices across consumers: enrollees with a relatively high coinsurance rate face greater differences in out-of-pocket prices across products than do enrollees with a low coinsurance rate. That is, the identifying price variation comes from coinsurance variation across plans, which we assume to be exogenous.

\section{[Table 5 Here]}

Across specifications, we find that the price sensitivity of Medicare enrollees is not significantly different from zero. Recall that commercially insured enrollees who use coupons have a zero out-of-pocket price, and are thus assumed to be unresponsive to price. The price sensitivity of commercially insured enrollees who do not use coupons has the expected sign and is highly significant $(p=0.001$ for the Price X Commercial interaction term), illustrating that coupons reduce the price elasticity of demand. 
However, even commercially insured enrollees who do not use coupons are relatively price inelastic. In our preferred specification, a $\$ 100$ increase in a drug's out-of-pocket price leads to only a $4.2 \%$ drop in market share on average. ${ }^{40}$ The overall own-price elasticity for commercially insured individuals is -0.104 . This is within the range of other estimates in the literature, albeit at the low end. ${ }^{41}$ Using data on retirees in the California Public Employees Retirement System (CalPERS), Chandra et al. (2010) estimate arc-elasticities for prescription drug consumption of -0.03 to -0.15 . Using data on Medicare Part D enrollees, Abaluck et al. (2018) and Dalton et al. (2020) estimate price elasticities of -0.13 and -0.38 , respectively. ${ }^{42}$ Einav et al. (2018) show that elasticity varies across drugs: they find a mean elasticity of -0.24 , with a standard deviation is 0.49. Given their sample consists of the most commonly purchased drugs, for which substitutes (including generics) are more readily available, it is unsurprising that elasticity for MS drugs would be on the low side.

The positive estimated coefficient on Coupon X Commercial indicates that coupon introduction is associated with an increase in demand for the commercial segment, consistent with a causal advertising effect of coupons that goes beyond the price effect of coupons on the demand elasticity. ${ }^{43}$ This point estimate is large and similar in magnitude whether we include drug-segment fixed effects (Column 1) or not (Columns 2-3). When drug-segment fixed effects are omitted, the estimated advertising effect coefficient is highly significant at $p<0.001$. The estimate is noisier when drug-segment fixed effects are included and identification comes from the only two drugs that introduce a coupon midway through the sample period $(p=.073)$. The estimated coefficient is

\footnotetext{
${ }^{40}$ We compute this by, for each drug, increasing out-of-pocket prices by $\$ 100$ and using the estimated demand equation to predict how the share of that drug changes for commercially insured individuals who do not use coupons. Then, we take the average of these effects across all drugs in the choice set. The effect of a $\$ 100$ out-of-pocket price increase is similar across drugs, ranging from $-3.2 \%$ to $-4.8 \%$ with a standard deviation of $0.5 \%$.

${ }^{41}$ In Appendix Section E.2, we show that assuming a higher price elasticity implies larger effects of coupons on drug prices.

${ }^{42}$ Dalton et al. (2020) report an elasticity of -0.54 in their estimation sample, and an elasticity of -0.38 in a nationally representative sample.

${ }^{43}$ The estimated effect of coupon introduction on overall demand (common to Medicare and commercial segments, Row 3 of Table 5) is not statistically significant in any specification. In our preferred specification, the point estimate is -.263 and noisy $(p=0.284)$. This estimate is likely to be downward-biased, however, as coupons may be introduced to stem a decrease in demand or in anticipation of a competitive threat. For this reason, we do not rely on the time-series impact of coupons on demand to estimate our coupon effect; rather, we focus on the differential effect for commercial and Medicare enrollees. Because we interpret this coefficient to reflect the timing of coupon introductions rather than a causal effect of coupon introduction, we will hold this effect constant when simulating the removal of coupons in Section 5 .
} 
quite large; it implies that removing a drug's coupon causes a $30.6 \%$ decrease in the market share of that drug, ceteris paribus. ${ }^{44}$ The effect of removing all coupons at once results in smaller decreases in shares for couponed drugs, on the order of $9.7 \%$.

\section{Counterfactual Simulations}

We use the demand estimates from Section 4 as an input to simulations that quantify the potential price effects of coupon introduction, following the framework of the model outlined in Section 3. We predict net prices in two scenarios: with and without the existence of coupons. ${ }^{45}$ In both cases, we solve the system of Nash-in-Nash first order conditions for pricesintroduced in Section 3.3 given our estimated model for consumer demand and our calibrated model of insurer-manufacturer negotiations. We assume a rebate percentage $r=0.15$ across all drugs and both segments, which is based on unpublished data from Kakani et al. (2020). ${ }^{46}$

In the following subsections, we report predictions for the effect of coupons on net prices and patients' out-of-pocket costs. We also provide predictions for the impact of coupons on insurer costs and hence (under reasonable assumptions) on average premiums. In Appendix Section E.2, we explore the robustness of our results to the assumptions made here.

\subsection{Impact of Coupons on Prices and Market Shares}

Table 6 shows the predicted impact of coupons on prices and market shares. We calibrate $\eta=0.69$ to provide a reasonable match of observed prices (Column 2) to their predicted values in the presence of coupons (Column 4). Appendix E.1 outlines our method for calibrating this parameter; note that values closer to 1 imply a greater share of surplus accrues to the pharmaceutical manufacturer. ${ }^{47}$ We assume that each manufacturer produces a single product and marginal production $\operatorname{costs} c_{j, t}$ are zero for all drugs (for MS drugs, external data imply marginal costs of around $3 \%$ of net

\footnotetext{
${ }^{44}$ We compute this comparative static using our main specification by removing the coupon for each ever-couponed drug in the sample one-by-one, observing how this affects the market share of the drug in question, and then taking the average of these effects across all ever-couponed drugs. The effect of coupon removal is similar across drugs, with effects ranging from $-28.5 \%$ to $-33.2 \%$ and a standard deviation of $2.0 \%$.

${ }^{45}$ Under a coupon ban, previous coupon users are now exposed to out-of-pocket prices, and we zero out the $\gamma^{\text {com }}$ advertising effect term in Equation 3. In Appendix Section E.2, we test sensitivity to allowing the advertising effect to remain when coupons are banned.

${ }^{46}$ Appendix E.2 shows our results are insensitive to using different values of the rebate, heterogeneous rebates based on SSR Health estimates, and allowing the rebate to change when coupons are banned.

${ }^{47}$ Appendix Section E.2 shows robustness to varying the bargaining weight.
} 
prices, see Appendix Section D.2). Our simulation sample is restricted to the time period where all drugs in our choice set are available, April 2015 through December 2017. Baseline simulated shares (Column 5) are close to the observed shares (Column 3). These baseline simulations include the observed set of coupons, shown in Column 1.

\section{[Table 6 Here]}

Columns 7-10 of the table provide the predicted equilibrium net prices and market shares of MS drugs in the scenario where all coupons are banned. The market shares of previously couponed drugs fall by 6-9\% as consumers substitute to never-couponed drugs, whose shares increase by about 25-37\% (these increases are larger due to the smaller baseline shares of non-couponed drugs). Prices fall for all drugs, with previously couponed drugs typically experiencing larger reductions in price when coupons are banned. ${ }^{48}$ The share-weighted average price reduction is $7.4 \%{ }^{49}$

\subsection{Impact on Premiums and Out-of-Pocket Costs}

Table 7 summarizes the predicted impact of the coupon ban on insurer costs and consumer out-of-pocket prices. Columns 5-7 report effects on out-of-pocket costs for different types of consumers, categorized by segment, coupon use, type of cost-sharing, and drug choice. ${ }^{50}$ Coupon removal would have sizeable distributional implications. Note first that out-of-pocket costs are higher on average for individuals in Medicare Advantage, whose plans often require coinsurance rather than copays. Medicare Advantage enrollees are predicted to experience a decrease in their out-of-pocket costs when coupons are banned as a result of lower list prices and hence lower coinsurance payments. ${ }^{51}$ In contrast, individuals with commercial insurance have lower pre-ban

\footnotetext{
${ }^{48}$ Removing coupons for some drugs leads to reductions in all drugs' prices because of substitution effects. If a drug's price is higher than those of its substitutes, the insurer's total cost decreases when that drug is dropped, and this puts downwards pressure on the drug's equilibrium markup. This reinforcement effect means that prices of substitute drugs tend to move together (Ho and Lee (2017)).

${ }^{49}$ Accounting for variation in our demand parameter estimates yields a $95 \%$ confidence interval of $5.5 \%$ to $9.7 \%$. See Appendix E.2 for details.

${ }^{50}$ We only model consumer cost sharing for the first MS drug prescription filled, and we do not account for out-of-pocket maxima that may be reached after that fill. Hence, our results may overstate the impact of a coupon ban on out-of-pocket payments, as some consumers will reach their out-of-pocket maximum in subsequent prescriptions.

${ }^{51}$ Note that Medicare Advantage enrollees who face copays in their prescription drug coverage may pay coinsurance rates in their medical insurance, which is utilized for the infused drug, Tysabri. This leads to small decreases in out-of-pocket costs for individuals who are listed as paying copays.
} 
out-of-pocket costs but the coupon ban increases these costs on average, as individuals who previously redeemed coupons must now pay their full copay or coinsurance amount. The increases are especially large for commercially insured individuals who pay coinsurance rather than copays. Appendix Figure E17 presents the distribution of the change in cost-sharing for each segment. Among commercially insured enrollees, those who do not use coupons and those who take non-couponed drugs experience reductions in their out-of-pocket expenses when coupons are removed.

We also consider the impact of coupons on premiums. As discussed above, a full premium-setting model would require a framework for consumer plan choice as an input into insurers' choice of premiums to maximize their profits. Instead, we simplify by assuming that the insurer markup and non-pharmaceutical costs in the full premium expression from Section 3 are held fixed when coupons are introduced and hence not relevant for our analysis; we normalize them to zero and consider the component of premiums that covers the insurer's drug costs. For MS drugs, this component is simply the average of $T C_{t}$ across enrollees. Our predictions for the effect of coupons on insurer costs (and hence premiums) are set out in Columns 2-4 of Table 7. Insurer costs decline substantially in both commercial and Medicare Advantage markets when coupons are removed. The average cost reduction is approximately $\$ 385$ per enrollee per month, or $7.6 \%$ of total costs. The decline is primarily caused by lower list prices and applies to all subgroups of individuals regardless of coupon use or type of cost-sharing. The shift in market share towards never-couponed drugs, whose prices are lower than couponed drugs, also contributes to the reduction in insurer costs and hence premiums.

\section{[Table 7 Here]}

Overall, under our assumptions, we find that banning coupons leads to premium reductions from reduced insurer costs that are nearly 4 times as large as the increases in out-of-pocket payments. Robustness tests, mentioned at relevant points throughout our discussion and detailed in the Appendix, demonstrate that our qualitative conclusions are not sensitive to varying the share of coupon users in the data, the size of the rebate and whether it adjusts following a coupon ban, and various other modeling assumptions. A coupon ban therefore has the potential to reduce costs for all enrollees, and if an appropriate redistributional mechanism can designed, may be both politically feasible and Pareto-optimal, at least in a static sense (i.e. not accounting for any effects of reduced manufacturer profits on pharmaceutical innovation, profits, and social 
surplus). We estimate net savings from a coupon ban would amount to $\$ 287$ per (monthly) prescription. Given annual net-of-rebate U.S. spending on multiple sclerosis drugs of around $\$ 15.9 \mathrm{~b}$, this translates into savings of about $\$ 950$ million per year from banning coupons on this category of drugs alone. ${ }^{52}$

\section{Discussion and Conclusions}

As branded drug prices continue to rise and new drugs are launched at ever higher prices, consumers and policymakers are intensifying their opposition to the status quo. However, current market prices reflect, among other things, the willingness of patients and insurers to pay the going rate. Lowering prices would require greater elasticity of downstream demand, more bargaining leverage on the part of insurers/PBMs, greater supply-side competition, regulation, or some combination of all four.

In this paper, we consider the role of manufacturer-sponsored coupons in contributing to higher spending through the channels of price as well as quantity. We pursue two complementary approaches. Our difference-in-differences analysis quantifies the short-term impact of coupon introduction by comparing responses of the commercially insured and Medicare-Advantage populations. Using a novel proprietary dataset with monthly data on drug quantities and net-of-rebate prices by enrollee segment, and focusing on drugs without bioequivalent generics, we find new coupon introductions between 2014 and 2016 led to an average increase in drug volume (as measured by days supplied) of more than 20 percent within 12 months post-coupon. We do not find any differential change in net-of-rebate prices, although theoretically coupons should enable manufacturers to offer lower rebates, ceteris paribus, for commercially-insured enrollees (or, similarly, to raise list prices and to offer higher rebates for the Medicare Advantage segment). Unfortunately, the post-coupon period of analysis is short, which may explain why we do not observe a differential effect on prices.

We supplement the difference-in-differences analysis by developing and estimating a model of drug choice, characterizing the bargaining between insurers and pharmaceutical manufacturers, and using the results of the drug choice model together with estimated rebate information as inputs to a simulated bargaining model. We use data on "first choices" of multiple sclerosis drugs by individuals in the HCCI claims data, over the period 2009 through 2017. Two of the drugs experience coupon introductions

\footnotetext{
${ }^{52}$ We estimate net-of-rebate spending as 85 percent of total invoiced spending on MS drugs in 2017, which was $\$ 18.7$ billion. Source: Medicines Use and Spending in the U.S. A Review of 2016 and Outlook to 2021. Report by the Quintiles, IMS Institute. May 2017
} 
during our study period. The estimation does not allow for a change in market size, an assumption that is necessary given the data available to us and likely less restrictive for this condition than for many others given the medical benefit and limited availability of substitute products. Our simulations indicate that prices of MS drugs are about 8 percent higher than they would be if coupons were banned. A coupon ban would raise out-of-pocket spending for MS patients who currently use coupons, but we predict the savings for insurers would be nearly 4 times as large. Net savings for MS drugs alone would amount to nearly a billion dollars annually. The predictions are robust to a wide set of changes in assumptions, ranging from the rate of coupon utilization to rebate levels as well as changes in these levels in the wake of a coupon ban.

A coupon ban would restore the ability of downstream insurers to use cost-sharing to steer patients toward preferred therapies, and in so doing, provide insurers with leverage to negotiate lower drug prices. Our findings imply that utilization of couponed drugs, and prices of both couponed and non-couponed drugs, would decline. However, the distributional effects of such a ban are significant. Many patients who currently utilize coupons would face higher cost-sharing for their medications. To mitigate the distributional effects of a coupon ban, it could be accompanied by a mechanism to transfer savings from removing coupons to consumers who would be made worse off. This could be achieved via fixed lump-sum contributions to the health savings accounts of enrollees with conditions treated by costly drugs, or through targeted premium reductions. The objective would be to preserve price incentives to utilize cost-effective therapies, while nevertheless minimizing the financial burden for patients with high drug costs. Notably, our results suggest that popular policy proposals such as capping cost-sharing, or requiring plans to shift from coinsurance to fixed (and low) copays are likely to lead to drug price inflation. These reforms would likely exacerbate the underlying problem of high prices while addressing a symptom.

Drug copay coupons are but one form of manufacturer-backed assistance to alleviate OOP costs. There are a number of additional programs, ranging from free samples to discount cards, that facilitate both price discrimination as well as patient access. Additional research on all of these programs would be helpful in developing comprehensive solutions to enable downstream drug demand to play a role in disciplining upstream prices. 


\section{References}

Abaluck, Jason, Jonathan Gruber, and Ashley Swanson. 2018. "Prescription drug use under Medicare Part D: A linear model of nonlinear budget sets." Journal of Public Economics, 164: 106-138.

Agha, Leila, Soomi Kim, and Danielle Li. 2020. "Insurance Design and Pharmaceutical Innovation." National Bureau of Economic Research, Cambridge, MA.

Baker, Andrew C., David F. Larcker, and Charles C.Y. Wang. 2022. "How much should we trust staggered difference-in-differences estimates?" Journal of Financial Economics, 144(2): 370-395.

Berndt, Ernst, Rena Conti, and Stephen Murphy. 2017. "The Landscape of US Generic Prescription Drug Markets, 2004-2016."

Borusyak, Kirill, Xavier Jaravel, and Jann Spiess. 2021. "Revisiting Event Study Designs: Robust and Efficient Estimation."

Callaway, Brantly, and Pedro H. C. Sant'Anna. 2020. "Difference-in-Differences with Multiple Time Periods."

Capps, Cory, David Dranove, and Mark Satterthwaite. 2003. "Competition and Market Power in Option Demand Markets." RAND Journal of Economics, 34(4): 737-763.

Chandra, Amitabh, Evan Flack, and Ziad Obermeyer. 2021. "The Health Costs of Cost-Sharing." NBER Working Paper Series No. 28439.

Chandra, Amitabh, Jonathan Gruber, and Robin McKnight. 2010. "Patient Cost-Sharing and Hospitalization Offsets in the Elderly." The American economic review, 100(1): 193 .

Corts, Kennth S. 1998. "Third-degree price discrimination in oligopoly: all-out competition and strategic commitment." RAND Journal of Economics, 29(2): 306-323.

Crawford, Gregory S., and Ali Yurukoglu. 2012. "The Welfare Effects of Bundling in Multichannel Television Markets." American Economic Review, 102(2): 643-685.

Dafny, Leemore, Christopher Ody, and Matt Schmitt. 2017. "When discounts raise costs: The effect of copay coupons on generic utilization." American Economic Journal: Economic Policy, 9(2): 91-123.

Dafny, Leemore, Kate Ho, and Edward Kong. 2023. "Code and public data for: How Do Copayment Coupons Affect Branded Drug Prices and Quantities Purchased?" American Economic Journal: Economic Policy. http://doi.org/10.3886/E185842V1.

Dalton, Christina M, Gautam Gowrisankaran, and Robert J Town. 2020. "Salience, Myopia, and Complex Dynamic Incentives: Evidence from Medicare Part D." The Review of Economic Studies, 87(2): 822-869. 
Draganska, Michaela, Daniel Klapper, and Sofia Villas-Boas. 2010. "A Larger Slice or a Larger Pie? An Empirical Investigation of Bargaining Power in the Distribution Channel." Marketing Science, 29(1): 57-74.

Dusetzina, Stacie B., Juliette Cubanski, Leonce Nshuti, Sarah True, Jack Hoadley, Drew Roberts, and Tricia Neuman. 2020. "Medicare Part D Plans Rarely Cover Brand-Name Drugs When Generics Are Available." https://doi.org/10.1377/hlthaff.2019.01694, 39(8): 1326-1333.

Einav, Liran, Amy Finkelstein, and Maria Polyakova. 2018. "Private provision of social insurance: Drug-specific price elasticities and cost sharing in Medicare Part D." American Economic Journal: Economic Policy, 10(3): 122-153.

Elsisi, Zizi, Ana L Hincapie, and Jeff Jianfei Guo. 2020. "Expenditure, Utilization, and Cost of Specialty Drugs for Multiple Sclerosis in the US Medicaid Population, 2008-2018." American health \& drug benefits, 13(2): 74-84.

Goodman-Bacon, Andrew. 2021. "Difference-in-differences with variation in treatment timing." Journal of Econometrics, 225(2): 254-277.

Gowrisankaran, G., A. Nevo, and R.J. Town. 2015. "Mergers When Prices Are Negotiated: Evidence from the Hospital Industry." American Economic Review, 105(1): 172-203.

Grennan, Matthew. 2013. "Price Discrimination and Bargaining: Empirical Evidence from Medical Devices." American Economic Review, 103(1): 147-177.

Grennan, Matthew, Kyle Myers, Ashley Swanson, and Aaron Chatterji. 2022. "No Free Lunch? Welfare Analysis of Firms Selling Through Expert Intermediaries." NBER Working Paper 24864.

Hartman, Micah, Anne B. Martin, Joseph Benson, and Aaron Catlin. 2020. "National health care spending in 2018: Growth driven by accelerations in medicare and private insurance spending." Health Affairs, 39(1): 8-17.

Ho, Kate, and Robin S. Lee. 2017. "Insurer Competition in Health Care Markets." Econometrica, 85(2): 379-417.

Ho, Kate, Joseph Hogan, and Fiona Scott-Morton. 2017. "The Impact of Consumer Inattention on Insurer Pricing in the Medicare Part D Program." RAND Journal of Economics, 48(4): 877-905.

Jordan, Matthew, Bouke Klein Teeselink, Nicholas Adolph, and Shane Frederick. 2020. "Discounts Shift the Demand Curve for Life-Saving Medications." SSRN Electronic Journal.

Kakani, Pragya, Michael Chernew, and Amitabh Chandra. 2020. "Rebates in the Pharmaceutical Industry: Evidence from Medicines Sold in Retail Pharmacies in the U.S." National Bureau of Economic Research Working Paper 26846. 
Lee, Chung Ying. 2020. "Pricing strategy and moral hazard: Copay coupons in pharmaceuticals." International Journal of Industrial Organization, 70(May 2017): 102611.

Lonergan, Roisín, Katie Kinsella, Marguerite Duggan, Sinead Jordan, Michael Hutchinson, and Niall Tubridy. 2009. "Discontinuing diseasemodifying therapy in progressive multiple sclerosis: can we stop what we have started?" Multiple sclerosis (Houndmills, Basingstoke, England), 15(12): 1528-31.

Lotvin, Alan M., William H. Shrank, Surya C. Singh, Benjamin P. Falit, and Troyen A. Brennan. 2014. "Specialty medications: Traditional and novel tools can address rising spending on these costly drugs." Health Affairs, 33(10): 1736-1744.

Mulcahy, Andrew W, Christopher M Whaley, Mahlet G Tebeka, Daniel Schwam, Nathaniel Edenfield, and Alejandro U Becerra-Ornelas. 2021. International Prescription Drug Price Comparisons: Current Empirical Estimates and Comparisons with Previous Studies. Santa Monica, CA:RAND Corporation.

Rambachan, Ashesh, and Jonathan Roth. 2023. "A More Credible Approach to Parallel Trends*." The Review of Economic Studies. rdad018.

Sen, Aditi P, So-Yeon Kang, Emaan Rashidi, Devoja Ganguli, Gerard Anderson, and G Caleb Alexander. 2021. "Characteristics of Copayment Offsets for Prescription Drugs in the United States." JAMA internal medicine.

Sood, Neeraj, Rocio Ribero, Martha Ryan, and Karen Van Nuys. 2020. "The Association Between Drug Rebates and List Prices." University of Southern California, Leonard D. Schaeffer Center for Health Policy and Economics.

Starner, Catherine I., G. Caleb Alexander, Kevin Bowen, Yang Qiu, Peter J. Wickersham, and Patrick P. Gleason. 2014. "Specialty drug coupons lower outof-pocket costs and may improve adherence at the risk of increasing premiums." Health Affairs, 33(10): 1761-1769.

Sun, Liyang, and Sarah Abraham. 2021. "Estimating dynamic treatment effects in event studies with heterogeneous treatment effects." Journal of Econometrics, 225(2): 175-199.

Torkildsen, O., K. M. Myhr, and L. Bø. 2016. "Disease-modifying treatments for multiple sclerosis - a review of approved medications." European Journal of Neurology, 23: 18-27.

Tunçel, Tuba. 2020. "Should We Prevent Off-Label Drug Prescriptions? Empirical Evidence from France." SSRN Electronic Journal.

Wallin, Mitchell T., William J. Culpepper, Jonathan D. Campbell, Lorene M. Nelson, Annette Langer-Gould, Ruth Ann Marrie, Gary R. Cutter, Wendy E. Kaye, Laurie Wagner, Helen Tremlett, Stephen L. Buka, Piyameth Dilokthornsakul, Barbara Topol, Lie H. Chen, and 
Nicholas G. Larocca. 2019. "The prevalence of MS in the United States: A population-based estimate using health claims data." Neurology, 92(10): E1029E1040. 


\section{Exhibits}

Figure 1: Share of branded drug spending with a copay coupon

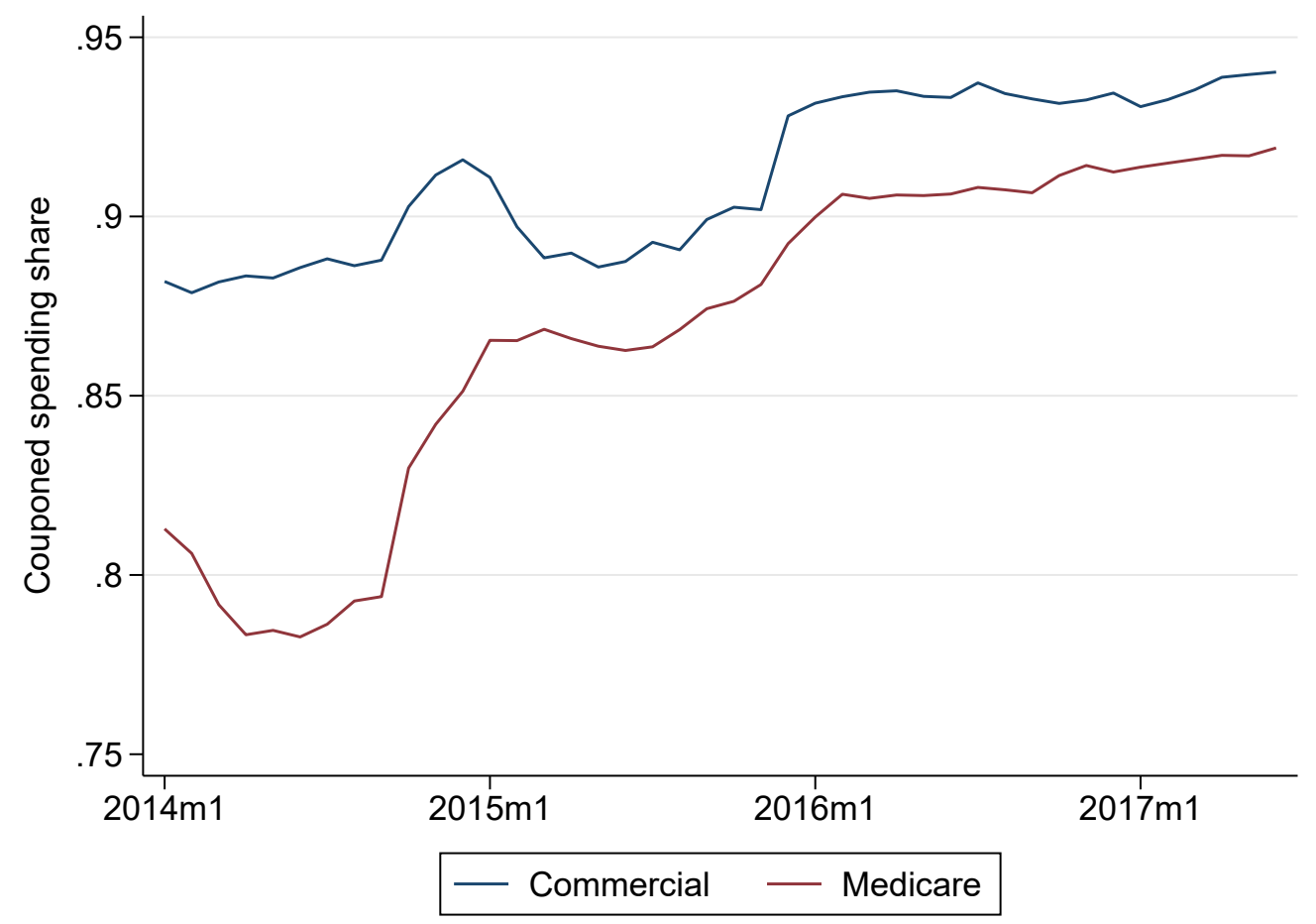

Notes: Figure shows the share of total spending on branded drugs accounted for by drugs with a copay coupon. First, we match coupon introduction dates to branded drugs in the PBM data. Then, we compute the share of monthly spending on drugs with an active coupon, separately for the commercial and Medicare segments. The data do not reflect rates of coupon use across drugs, which we do not observe. Coupons are banned for Medicare claims; however, a significant share of branded drug spending in Medicare is accounted for by drugs that have introduced coupons. 
Table 1: Effect of Sample Restrictions

\begin{tabular}{l|cc|cc}
\hline & \multicolumn{2}{|c|}{ Medicare Advantage } & \multicolumn{2}{c}{ Commercial } \\
\hline Sample & $\begin{array}{c}\text { Share of spending } \\
(\%)\end{array}$ & $\begin{array}{c}\text { Unique } \\
\text { Drugs }\end{array}$ & $\begin{array}{c}\text { Share of spending } \\
(\%)\end{array}$ & $\begin{array}{c}\text { Unique } \\
\text { Drugs }\end{array}$ \\
& 100 & 1929 & 100 & 1999 \\
Original PBM data & 97.5 & 1608 & 97.9 & 1656 \\
Merged PBM and FDA data & 64.7 & 758 & 63.7 & 762 \\
$\begin{array}{l}\text { Branded drugs only } \\
\text { Brands without generic equivalents }\end{array}$ & 53.8 & 496 & 54.6 & 507 \\
$\begin{array}{l}\text { Restrict to drugs with similar } \\
\text { utilization across segments }\end{array}$ & 48.3 & 366 & 47.1 & 366 \\
$\begin{array}{l}\text { Restrict to switchers only } \\
\text { Restrict to switchers with sufficient } \\
\text { pre- and post-period observations }\end{array}$ & 4.4 & 56 & 4.4 & 56 \\
\hline
\end{tabular}

Notes: "Drugs" are defined by our drug name standardization process and may correspond to multiple NDC9 codes. The merged PBM and FDA data (Row 2) include the set of NDC9 codes in the PBM data with a match in the FDA data, excluding indications for which at least 50 percent of PBM spending lacks a match in the FDA data. 
Table 2: Descriptive Statistics (Drug-Month Sample)

\begin{tabular}{|c|c|c|c|c|}
\hline & Always & Never & $\begin{array}{l}\text { Switch } \\
\text { (all) }\end{array}$ & $\begin{array}{c}\text { Switch } \\
\text { (estimation sample) }\end{array}$ \\
\hline $\begin{array}{l}\text { Statistics by Category } \\
\text { Number of drugs } \\
\% \text { commercial spending } \\
\% \text { Medicare spending }\end{array}$ & $\begin{array}{c}275 \\
89.49 \\
89.32\end{array}$ & $\begin{array}{c}35 \\
1.20 \\
1.60\end{array}$ & $\begin{array}{c}56 \\
9.31 \\
9.08\end{array}$ & $\begin{array}{c}33 \\
6.07 \\
7.41\end{array}$ \\
\hline $\begin{array}{l}\text { Top MCI (number of drugs) } \\
\text { Second MCI (number of drugs) } \\
\text { Third MCI (number of drugs) }\end{array}$ & $\begin{array}{l}\text { Diabetes (29) } \\
\text { HIV (22) } \\
\text { Asthma (19) }\end{array}$ & $\begin{array}{l}\text { Diabetes }(5) \\
\text { Asthma }(3) \\
\text { HBP } / \text { Heart } \\
\text { Disease }(2)^{\mathrm{a}}\end{array}$ & $\begin{array}{c}\text { Cancer (7) } \\
\text { Ophthalmic (5) } \\
\text { Pain/ } \\
\text { Inflammation (4) }\end{array}$ & $\begin{array}{c}\text { Cancer (7) } \\
\text { Ophthalmic (4) } \\
\text { Blood Cell } \\
\text { Deficiency }(2)^{\mathrm{b}}\end{array}$ \\
\hline $\begin{array}{l}\text { Drugs by route, \% (number of drugs) } \\
\text { Topical } \\
\text { Oral } \\
\text { Injection } \\
\text { Other }\end{array}$ & $\begin{array}{l}4(11) \\
61(167) \\
15(40) \\
21(57)\end{array}$ & $\begin{array}{c}3(1) \\
46(16) \\
17(6) \\
34(12)\end{array}$ & $\begin{array}{c}9(5) \\
55(31) \\
13(7) \\
23(13)\end{array}$ & $\begin{aligned} 9 & (3) \\
55 & (18) \\
9 & (3) \\
27 & (9)\end{aligned}$ \\
\hline $\mathrm{N}$ (drug-month observations) & 19,898 & 2,402 & 4,286 & 2,700 \\
\hline $\begin{array}{l}\text { Statistics by Drug } \\
\text { Average list price }(\$)\end{array}$ & $\begin{array}{l}1,642 \\
(3788)\end{array}$ & $\begin{array}{c}369 \\
(367)\end{array}$ & $\begin{array}{l}1,945 \\
(3006)\end{array}$ & $\begin{array}{l}2,585 \\
(3482)\end{array}$ \\
\hline Average commercial patient cost share (\%) & $\begin{array}{l}16.06 \\
(15.49)\end{array}$ & $\begin{array}{c}23.24 \\
(21.58)\end{array}$ & $\begin{array}{l}17.51 \\
(18.12)\end{array}$ & $\begin{array}{c}16.19 \\
(17.06)\end{array}$ \\
\hline Average Medicare patient cost share (\%) & $\begin{array}{l}12.69 \\
(12.4)\end{array}$ & $\begin{array}{l}17.65 \\
(13.75)\end{array}$ & $\begin{array}{l}13.34 \\
(13.37)\end{array}$ & $\begin{array}{c}13.79 \\
(14)\end{array}$ \\
\hline Monthly average days supplied & $\begin{array}{c}64,392 \\
(180210)\end{array}$ & $\begin{array}{c}8,657 \\
(16779)\end{array}$ & $\begin{array}{l}15,321 \\
(27604)\end{array}$ & $\begin{array}{l}13,284 \\
(20352)\end{array}$ \\
\hline Average CAGR in price $(\%)$ & $\begin{array}{c}6.89 \\
(10.23)\end{array}$ & $\begin{array}{c}9.02 \\
(10.5)\end{array}$ & $\begin{array}{c}8.01 \\
(9.77)\end{array}$ & $\begin{array}{l}10.18 \\
(10.92)\end{array}$ \\
\hline Average CAGR in days supplied (\%) & $\begin{array}{c}38.72 \\
(93.71)\end{array}$ & $\begin{array}{l}14.00 \\
(58.27)\end{array}$ & $\begin{array}{c}67.77 \\
(130.81)\end{array}$ & $\begin{array}{c}24.01 \\
(62.78)\end{array}$ \\
\hline
\end{tabular}

Notes: Panel A shows statistics at the drug category level, for drugs that are always couponed in our sample (Column 1), never couponed in our sample (Column 2), introduce a coupon (switchers) during our study period (Column 3), and introduce a coupon during our study period and are observed for 9 months before and 12 months after coupon introduction (i.e., our estimation sample, in Column 4). Panel B shows drug-level means (standard deviations in parentheses) for the set of drugs in each category. For both panels, the sample is limited to branded drugs utilized in both commercial and Medicare populations and with no generic equivalent available as of July 2017. Average list price is reported in 2014 dollars per 30-day equivalent script from the 2014 Medicare Part D data (or the first year the drug appears in Part D data). The compound annual growth rate (CAGR) in net-of-rebate price for each drug is computed from the first quarter to the last quarter that the drug is observed in the PBM data. MCI refers to the most common indication for each drug.

a Tie between five indications with two drugs each: high blood pressure/heart disease, inflammation/immune disorders, constipation, nausea/vomiting, and infections.

b Tie between five indications with two drugs each: eye infection, blood cell deficiency, pain/inflammation, skin conditions, and erectile dysfunction. 
Figure 2: Effects of Coupons on Utilization and Price

(a) $\ln$ (days supply), unweighted

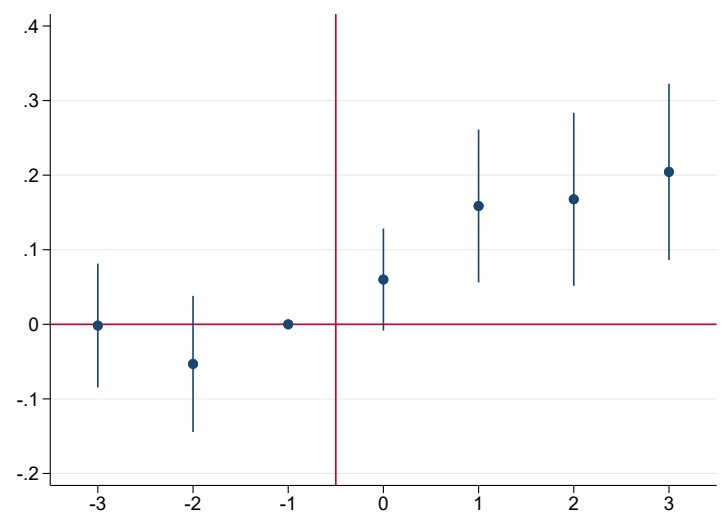

(c) $\ln$ (price), unweighted

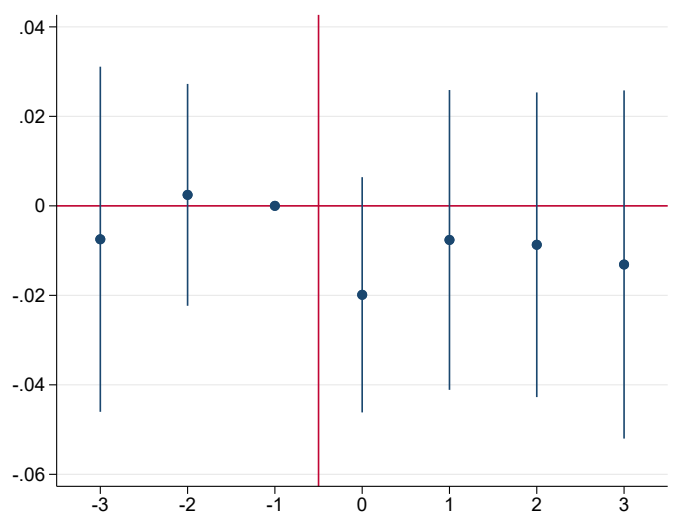

(b) $\ln$ (days supply), weighted

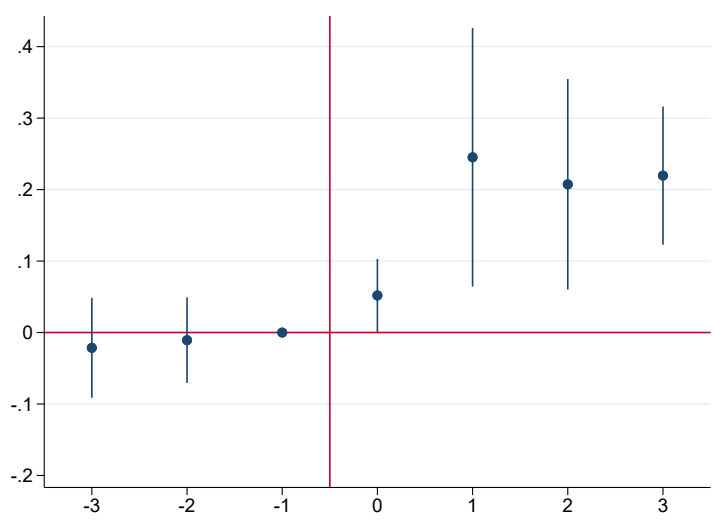

(d) $\ln$ (price), weighted

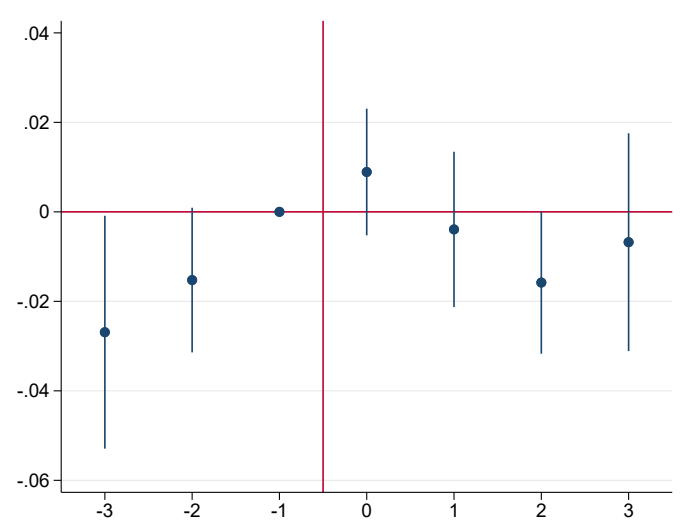

Notes: Each graph plots coefficient estimates and 95\% confidence intervals from a regression of $\ln ($ days supply) or $\ln$ (price) on quarter relative to coupon introduction. Coefficients plotted reflect the response in the commercial segment relative to the response in Medicare. All specifications are estimated on a balanced panel of data for switchers, including monthly observations from 9 months prior to coupon introduction through 12 months after coupon introduction. The quarter prior to introduction is omitted. Panels (a) and (c) show unweighted results, while Panels (b) and (d) show results weighted by each drug's share of spending in each segment in the 6 months prior to coupon introduction. 
Table 3: Difference-in-Differences Estimates

\begin{tabular}{|c|c|c|c|c|}
\hline Commercial $\times$ & \multicolumn{2}{|c|}{$\ln$ (supply) } & \multicolumn{2}{|c|}{$\ln ($ price $)$} \\
\hline$Q=-3$ & $\begin{array}{l}-0.002 \\
(0.041)\end{array}$ & $\begin{array}{l}-0.021 \\
(0.034)\end{array}$ & $\begin{array}{l}-0.007 \\
(0.019)\end{array}$ & $\begin{array}{r}-0.027^{* *} \\
(0.013)\end{array}$ \\
\hline$Q=-2$ & $\begin{array}{l}-0.053 \\
(0.045)\end{array}$ & $\begin{array}{l}-0.011 \\
(0.029)\end{array}$ & $\begin{array}{c}0.002 \\
(0.012)\end{array}$ & $\begin{array}{c}-0.015^{*} \\
(0.008)\end{array}$ \\
\hline$Q=-1$ & 0 & 0 & 0 & 0 \\
\hline$Q=0$ & $\begin{array}{l}0.060^{*} \\
(0.034)\end{array}$ & $\begin{array}{c}0.052^{* *} \\
(0.025)\end{array}$ & $\begin{array}{l}-0.020 \\
(0.013)\end{array}$ & $\begin{array}{c}0.009 \\
(0.007)\end{array}$ \\
\hline$Q=1$ & $\begin{array}{c}0.159^{* * *} \\
(0.050)\end{array}$ & $\begin{array}{c}0.245^{* * *} \\
(0.089)\end{array}$ & $\begin{array}{l}-0.008 \\
(0.016)\end{array}$ & $\begin{array}{l}-0.004 \\
(0.009)\end{array}$ \\
\hline$Q=2$ & $\begin{array}{c}0.168^{* * *} \\
(0.057)\end{array}$ & $\begin{array}{c}0.207^{* * *} \\
(0.072)\end{array}$ & $\begin{array}{l}-0.009 \\
(0.017)\end{array}$ & $\begin{array}{l}-0.016^{*} \\
(0.008)\end{array}$ \\
\hline$Q=3$ & $\begin{array}{c}0.204^{* * *} \\
(0.058)\end{array}$ & $\begin{array}{c}0.220^{* * *} \\
(0.047)\end{array}$ & $\begin{array}{l}-0.013 \\
(0.019)\end{array}$ & $\begin{array}{l}-0.007 \\
(0.012)\end{array}$ \\
\hline Weights & $\mathrm{N}$ & Y & $\mathrm{N}$ & Y \\
\hline
\end{tabular}

Notes: Standard errors are clustered at the drug level. Weights are defined as the share of within-segment spending accounted for by the drug in the 6 months before coupon introduction, normalized so that average weights in each segment are equal. $Q=0$ represents the first three months after coupon introduction. For each drug, we include only observations for the 9 months prior and 12 months after coupon introduction. The unit of observation is the drug-month-segment. All specifications include drug-segment and year-month fixed effects. $\mathrm{N}=1,386$. 
Figure 3: Leave-one-out estimates of the coupon effect on drug quantity

(a) Unweighted

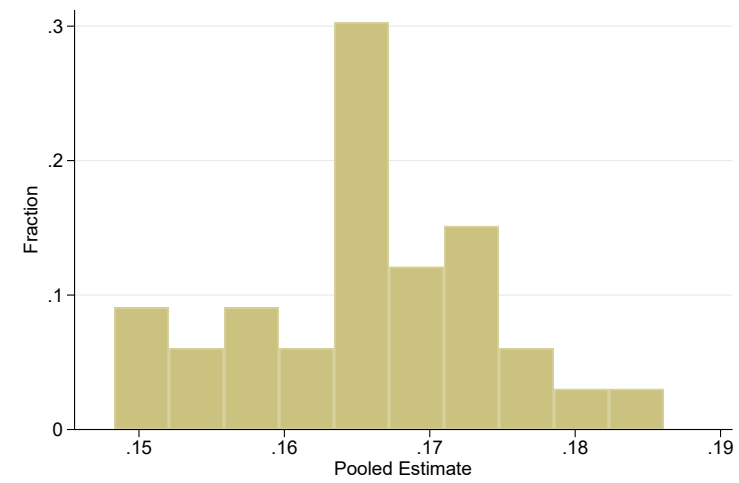

(b) Weighted

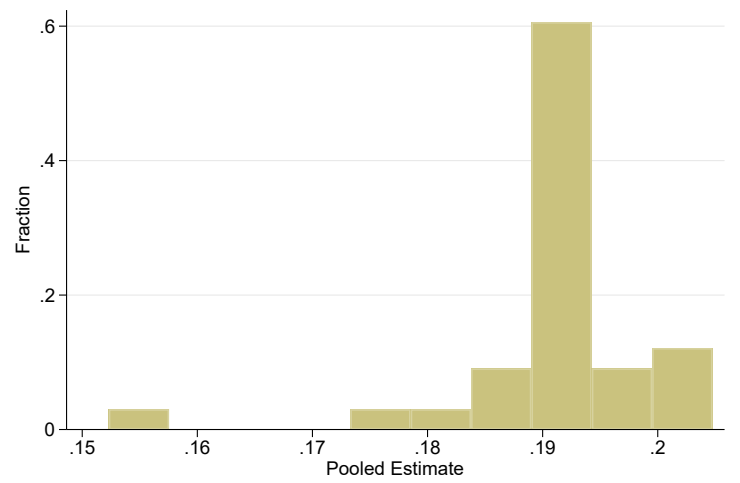

Notes: Histograms show the distribution of pooled estimates of the effect of coupons on $\ln ($ days supply $)$ when different drugs are excluded from the estimation sample. All specifications are estimated on a balanced panel of data for switchers, including monthly observations from 9 months prior to coupon introduction through 12 months after coupon introduction. The quarter prior to introduction is omitted. Panel (a) shows unweighted results; Panel (b) shows results weighted by each drug's share of segment-specific spending in the 6 months prior to coupon introduction. 
Table 4: Descriptive Statistics for HCCI Estimation Sample

\begin{tabular}{l|cc|cc|cc|cc}
\multicolumn{1}{c}{ Panel A: Commercial } \\
\hline \hline \multirow{1}{*}{ Drug } & \multicolumn{2}{|c|}{ Share } & Avg. OOP Price (\$) & \multicolumn{2}{c|}{ SD (\$) } & \multicolumn{2}{c}{ Avg. Allowed Amt. (\$) } \\
& $2009-2011$ & $2015-2017$ & $2009-2011$ & $2015-2017$ & $2009-2011$ & $2015-2017$ & $2009-2011$ & $2015-2017$ \\
& $(1)$ & $(2)$ & $(3)$ & $(4)$ & $(5)$ & $(6)$ & $(7)$ & $(8)$ \\
\hline Aubagio & - & 0.126 & - & 243 & - & 559 & - & 5,742 \\
Avonex & 0.211 & 0.078 & 126 & 248 & 354 & 576 & 2,706 & 5,900 \\
Betaseron & 0.121 & 0.036 & 128 & 259 & 361 & 609 & 2,750 & 6,260 \\
Copaxone20 & 0.399 & 0.031 & 135 & 275 & 391 & 655 & 2,998 & 6,765 \\
Copaxone40 & - & 0.311 & - & 237 & - & 543 & - & 5,567 \\
Gilenya & 0.086 & 0.083 & 210 & 259 & 571 & 612 & 3,798 & 6,267 \\
Glatopa & - & 0.008 & - & 234 & - & 548 & - & 5,415 \\
Plegridy & - & 0.026 & - & 247 & - & 574 & - & 5,873 \\
Rebif & 0.159 & 0.056 & 124 & 260 & 346 & 612 & 2,634 & 6,275 \\
Tecfidera & - & 0.230 & - & 262 & - & 618 & - & 6,345 \\
Tysabri & 0.074 & 0.015 & 284 & 671 & 518 & 1,058 & 3,251 & 5,908 \\
\hline
\end{tabular}

Panel B: Medicare

\begin{tabular}{l|cc|cc|cc|cc}
\hline \hline \multirow{1}{*}{ Drug } & \multicolumn{2}{|c|}{ Share } & \multicolumn{2}{c|}{ Avg. OOP Price (\$) } & \multicolumn{2}{c|}{ SD (\$) } & \multicolumn{2}{c}{ Avg. Allowed Amt. (\$) } \\
& $2009-2011$ & $2015-2017$ & $2009-2011$ & $2015-2017$ & $2009-2011$ & $2015-2017$ & $2009-2011$ & $2015-2017$ \\
& $(1)$ & $(2)$ & $(3)$ & $(4)$ & $(5)$ & $(6)$ & $(7)$ & $(8)$ \\
\hline Aubagio & - & 0.168 & - & 515 & - & 488 & - & 5,672 \\
Avonex & 0.331 & 0.101 & 260 & 508 & 221 & 482 & 2,839 & 5,584 \\
Betaseron & 0.071 & 0.140 & 263 & 548 & 222 & 521 & 2,882 & 6,040 \\
Copaxone20 & 0.396 & 0.028 & 297 & 599 & 253 & 570 & 3,235 & 6,592 \\
Copaxone40 & - & 0.237 & - & 490 & - & 463 & - & 5,376 \\
Gilenya & 0.054 & 0.014 & 359 & 550 & 286 & 525 & 3,755 & 6,072 \\
Glatopa & - & 0.008 & - & 470 & - & 482 & - & 5,122 \\
Plegridy & - & 0.026 & - & 512 & - & 487 & - & 5,634 \\
Rebif & 0.130 & 0.057 & 253 & 544 & 214 & 517 & 2,760 & 5,998 \\
Tecfidera & - & 0.211 & - & 558 & - & 532 & - & 6,155 \\
Tysabri & 0.039 & 0.014 & 218 & 393 & 481 & 965 & 2,831 & 5,494 \\
\hline
\end{tabular}

Note: Table shows descriptive statistics by drug for the HCCI estimation sample, separately by market segment. Statistics for the first and last three years of the sample are shown. No new drugs were approved between 2009 and 2011. Only Glatopa (approved in April 2015) enters the market between 2015 and 2017. Columns 1-2 show market shares for each drug; Columns 3-4 show average out-of-pocket costs (per first prescription); Columns 5-6 show the standard deviation of out-of-pocket costs across enrollees (per first prescription); and Columns 7-8 show average allowed amounts per first prescription (a measure of list prices) The estimation sample contains $\mathrm{N}=3,483$ commercially insured enrollees and $\mathrm{N}=1,098$ Medicare Advantage enrollees. 
Table 5: Maximum Likelihood Estimates

\begin{tabular}{|c|c|c|c|}
\hline & (1) & (2) & (3) \\
\hline OOP Price & $\begin{array}{c}0.036 \\
(0.023)\end{array}$ & $\begin{array}{c}0.037 \\
(0.023)\end{array}$ & $\begin{array}{l}0.049^{+} \\
(0.026)\end{array}$ \\
\hline OOP Price X Commercial & $\begin{array}{c}-0.081^{* *} \\
(0.027)\end{array}$ & $\begin{array}{c}-0.084^{* *} \\
(0.027)\end{array}$ & $\begin{array}{c}-0.099^{* *} \\
(0.029)\end{array}$ \\
\hline Coupon X Commercial & $\begin{array}{c}0.376^{* *} \\
(0.085)\end{array}$ & $\begin{array}{c}0.357^{* *} \\
(0.085)\end{array}$ & $\begin{array}{c}0.373^{+} \\
(0.208)\end{array}$ \\
\hline Coupon & $\begin{array}{l}-0.134 \\
(0.193)\end{array}$ & $\begin{array}{l}-0.223 \\
(0.193)\end{array}$ & $\begin{array}{l}-0.263 \\
(0.246)\end{array}$ \\
\hline Drug Age (6-12 mo) & & $\begin{array}{c}0.635^{+} \\
(0.268)\end{array}$ & $\begin{array}{l}0.632^{+} \\
(0.269)\end{array}$ \\
\hline Drug Age (1-2 yr) & & $\begin{array}{c}1.328^{* *} \\
(0.280)\end{array}$ & $\begin{array}{c}1.300 \text { ** } \\
(0.280)\end{array}$ \\
\hline Drug Age (2-3 yr) & & $\begin{array}{c}1.5622^{* *} \\
(0.322)\end{array}$ & $\begin{array}{c}1.518^{* *} \\
(0.322)\end{array}$ \\
\hline Drug Age (3-5 yr) & & $\begin{array}{c}1.843^{* *} \\
(0.353)\end{array}$ & $\begin{array}{c}1.821^{* *} \\
(0.354)\end{array}$ \\
\hline Drug Age $(5+$ yr $)$ & & $\begin{array}{c}1.850^{* *} \\
(0.420)\end{array}$ & $\begin{array}{c}1.816^{* *} \\
(0.420)\end{array}$ \\
\hline Drug Age (6-12 mo) X Female & & $\begin{array}{l}-0.366 \\
(0.288)\end{array}$ & $\begin{array}{l}-0.351 \\
(0.288)\end{array}$ \\
\hline Drug Age (1-2 yr) X Female & & $\begin{array}{c}-0.508^{+} \\
(0.257)\end{array}$ & $\begin{array}{c}-0.493^{+} \\
(0.257)\end{array}$ \\
\hline Drug Age (2-3 yr) X Female & & $\begin{array}{c}-0.640^{+} \\
(0.263)\end{array}$ & $\begin{array}{c}-0.624^{+} \\
(0.263)\end{array}$ \\
\hline Drug Age (3-5 yr) X Female & & $\begin{array}{c}-0.844^{* *} \\
(0.261)\end{array}$ & $\begin{array}{c}-0.8366^{* *} \\
(0.261)\end{array}$ \\
\hline Drug Age $(5+$ yr $)$ X Female & & $\begin{array}{l}-0.319 \\
(0.231)\end{array}$ & $\begin{array}{l}-0.315 \\
(0.231) \\
\end{array}$ \\
\hline Drug FE & Yes & Yes & Yes \\
\hline Drug-Year FE & Yes & Yes & Yes \\
\hline Drug-Segment FE & No & No & Yes \\
\hline
\end{tabular}

Standard errors in parentheses

${ }^{+} p<0.10,{ }^{*} p<0.05,{ }^{* *} p<0.01$

Notes: Table shows maximum likelihood estimates of Equations 2 and 3 for $\mathrm{N}=4,581$ enrollees. Column 1 shows estimates with drug fixed effects, drug-year fixed effects, and drugsegment fixed effects. Column 2 shows estimates omitting drug-segment fixed effects. Column 3 additionally omits controls for the age of each drug (relative to its approval date) when each choice is made and interactions between drug age and patient gender. 
Table 6: Impact of a Coupon Ban on Prices and Shares

\begin{tabular}{|c|c|c|c|c|c|c|c|c|c|}
\hline \multirow[b]{2}{*}{ Drug } & \multirow[b]{2}{*}{$\begin{array}{c}\text { Coupon } \\
\text { Status } \\
(1)\end{array}$} & \multicolumn{2}{|c|}{ Data } & \multicolumn{2}{|c|}{ Simulation: Baseline } & \multicolumn{4}{|c|}{ Simulation: Coupons Banned } \\
\hline & & $\begin{array}{c}\text { Net } \\
\text { Price }(\$) \\
(2)\end{array}$ & $\begin{array}{c}\text { Share } \\
(3)\end{array}$ & $\begin{array}{c}\text { Net } \\
\text { Price }(\$) \\
(4)\end{array}$ & $\begin{array}{c}\text { Share } \\
(5)\end{array}$ & $\begin{array}{c}\text { Net } \\
\text { Price }(\$) \\
(6)\end{array}$ & $\begin{array}{c}\text { Share } \\
(7)\end{array}$ & $\begin{array}{c}\Delta \\
\text { Price }(\%) \\
(8)\end{array}$ & $\begin{array}{c}\Delta \\
\text { Share }(\%) \\
(9)\end{array}$ \\
\hline Aubagio & Always & 4941 & 0.148 & 5077 & 0.139 & 4704 & 0.130 & -7.4 & -6.4 \\
\hline Avonex & Never & 5071 & 0.076 & 4940 & 0.082 & 4646 & 0.103 & -5.9 & 26.6 \\
\hline Betaseron & Never & 5395 & 0.044 & 4937 & 0.055 & 4635 & 0.068 & -6.1 & 24.8 \\
\hline Copaxone20 & Aug 2011 & 5787 & 0.030 & 4873 & 0.029 & 4569 & 0.037 & -6.2 & 28.5 \\
\hline Copaxone40 & Always & 4753 & 0.308 & 5198 & 0.303 & 4799 & 0.280 & -7.7 & -7.7 \\
\hline Gilenya & Oct 2011 & 5420 & 0.066 & 4989 & 0.067 & 4563 & 0.061 & -8.5 & -8.8 \\
\hline Glatopa & Never & 4538 & 0.008 & 4848 & 0.008 & 4544 & 0.011 & -6.3 & 31.0 \\
\hline Plegridy & Never & 5060 & 0.028 & 4870 & 0.027 & 4567 & 0.035 & -6.2 & 29.2 \\
\hline Rebif & Always & 5390 & 0.054 & 4998 & 0.056 & 4616 & 0.053 & -7.6 & -6.7 \\
\hline Tecfidera & Always & 5486 & 0.224 & 5135 & 0.222 & 4738 & 0.205 & -7.7 & -7.5 \\
\hline Tysabri & Never & 5011 & 0.015 & 4499 & 0.013 & 4120 & 0.017 & -8.4 & 36.6 \\
\hline
\end{tabular}

Notes: Table shows observed prices (computed as $0.85 \times$ the average allowed amount) and market shares in the simulation sample (Columns 2-3). Columns 4-5 show simulated net prices and shares at baseline, where coupons are as observed in the data (Column 1). Columns 6-10 show results from a simulation where all existing coupons are banned. Columns 6-7 show the resulting net prices and market shares; Columns 8-9 express the effects of the coupon ban as a percent of baseline simulated values. The average change in net price is $-7.4 \%$, weighting by the baseline simulated shares in Column 5 . 
Table 7: Impact of a Coupon Ban on Insurer and Out-of-Pocket Costs

\begin{tabular}{|c|c|c|c|c|c|c|c|}
\hline Group & $\begin{array}{l}\mathrm{N} \\
(1)\end{array}$ & $\begin{array}{c}\text { Insurer costs } \\
\text { with coupons } \\
\text { (2) }\end{array}$ & $\begin{array}{c}\text { Insurer costs } \\
\text { coupon ban } \\
\text { (3) }\end{array}$ & $\begin{array}{c}\Delta \text { Insurer } \\
\text { Costs } \\
(4)\end{array}$ & $\begin{array}{c}\text { OOP Cost } \\
\text { with coupons } \\
(5)\end{array}$ & $\begin{array}{c}\text { OOP Cost } \\
\text { coupons ban } \\
(6)\end{array}$ & $\begin{array}{c}\Delta \text { OOP } \\
\text { Costs } \\
(7)\end{array}$ \\
\hline Commercial & 1,104 & 5,081 & 4,690 & -391 & 86 & 232 & 146 \\
\hline Coupon Users & 828 & 5,082 & 4,690 & -392 & 33 & 232 & 199 \\
\hline Non-users & 276 & 5,077 & 4,690 & -387 & 245 & 232 & -14 \\
\hline Copay & 910 & 5,080 & 4,692 & -388 & 31 & 76 & 45 \\
\hline Coinsurance & 194 & 5,086 & 4,683 & -403 & 343 & 961 & 618 \\
\hline Couponed Drugs & $895 \rightarrow 806$ & 5,127 & 4,731 & -396 & 57 & 240 & 183 \\
\hline Non-couponed Drugs & $209 \rightarrow 298$ & 4,888 & 4,584 & -304 & 234 & 225 & -9 \\
\hline Medicare & 388 & 5,065 & 4,698 & -367 & 542 & 503 & -38 \\
\hline Copay & 120 & 5,066 & 4,698 & -368 & 164 & 154 & -10 \\
\hline Coinsurance & 268 & 5,064 & 4,697 & -367 & 711 & 659 & -51 \\
\hline Couponed Drugs & $282 \rightarrow 282$ & 5,127 & 4,736 & -391 & 550 & 509 & -41 \\
\hline Non-couponed Drugs & $106 \rightarrow 106$ & 4,901 & 4,598 & -302 & 521 & 490 & -31 \\
\hline Overall & 1,492 & 5,077 & 4,692 & -385 & 204 & 302 & 98 \\
\hline
\end{tabular}

Notes: Table shows insurer and out-of-pocket costs with and without coupons, separately for selected subgroups. Insurer costs are expressed in $\$$ per member per month; out-of-pocket costs are expressed in $\$$ per prescription for enrollees' first observed choice. Results average over coupon users and nonusers (except where otherwise indicated) based on our assumption that $75 \%$ share of commercially insured patients use coupons. Copay/coinsurance designations apply at the patient level. Patients are coded as paying copays or coinsurance based on the nature of their prescription drug insurance (see Appendix Section B.6). Patients facing prescription drug copays may have medical insurance requiring coinsurance. The number of individuals choosing couponed drugs may change after coupons are banned; this is reflected in Column 1 in the format [number of individuals when coupons are available] $\longrightarrow$ [number of individuals when coupons are banned]. 